\title{
Under pressure: phenotypic divergence and convergence associated with microhabitat adaptations in Triatominae
}

\author{
Fernando Abad-Franch 1,2* ${ }^{\text {D }}$, Fernando A. Monteiro ${ }^{3,4}$, Márcio G. Pavan ${ }^{5}$, James S. Patterson², \\ M. Dolores Bargues ${ }^{6}$, M. Ángeles Zuriaga $^{6}$, Marcelo Aguilar ${ }^{7,8}$, Charles B. Beard ${ }^{4}$, Santiago Mas-Coma ${ }^{6}$ and \\ Michael A. Miles²
}

\begin{abstract}
Background: Triatomine bugs, the vectors of Chagas disease, associate with vertebrate hosts in highly diverse ecotopes. It has been proposed that occupation of new microhabitats may trigger selection for distinct phenotypic variants in these blood-sucking bugs. Although understanding phenotypic variation is key to the study of adaptive evolution and central to phenotype-based taxonomy, the drivers of phenotypic change and diversity in triatomines remain poorly understood.
\end{abstract}

Methods/results: We combined a detailed phenotypic appraisal (including morphology and morphometrics) with mitochondrial cytb and nuclear ITS2 DNA sequence analyses to study Rhodnius ecuadoriensis populations from across the species' range. We found three major, naked-eye phenotypic variants. Southern-Andean bugs primarily from vertebrate-nest microhabitats (Ecuador/Peru) are typical, light-colored, small bugs with short heads/wings. NorthernAndean bugs from wet-forest palms (Ecuador) are dark, large bugs with long heads/wings. Finally, northern-lowland bugs primarily from dry-forest palms (Ecuador) are light-colored and medium-sized. Wing and (size-free) head shapes are similar across Ecuadorian populations, regardless of habitat or phenotype, but distinct in Peruvian bugs. Bayesian phylogenetic and multispecies-coalescent DNA sequence analyses strongly suggest that Ecuadorian and Peruvian populations are two independently evolving lineages, with little within-lineage phylogeographic structuring or differentiation.

Conclusions: We report sharp naked-eye phenotypic divergence of genetically similar Ecuadorian R. ecuadoriensis (nest-dwelling southern-Andean vs palm-dwelling northern bugs; and palm-dwelling Andean vs lowland), and sharp naked-eye phenotypic similarity of typical, yet genetically distinct, southern-Andean bugs primarily from vertebratenest (but not palm) microhabitats. This remarkable phenotypic diversity within a single nominal species likely stems from microhabitat adaptations possibly involving predator-driven selection (yielding substrate-matching camouflage coloration) and a shift from palm-crown to vertebrate-nest microhabitats (yielding smaller bodies and shorter and stouter heads). These findings shed new light on the origins of phenotypic diversity in triatomines, warn against

*Correspondence: abadfr@yahoo.com

${ }^{1}$ Núcleo de Medicina Tropical, Faculdade de Medicina, Universidade de Brasília, Brasília, Brazil

Full list of author information is available at the end of the article

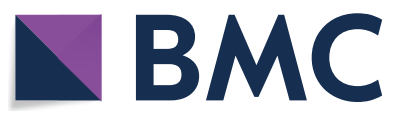

(c) The Author(s) 2021. This article is licensed under a Creative Commons Attribution 4.0 International License, which permits use, sharing, adaptation, distribution and reproduction in any medium or format, as long as you give appropriate credit to the original author(s) and the source, provide a link to the Creative Commons licence, and indicate if changes were made. The images or other third party material in this article are included in the article's Creative Commons licence, unless indicated otherwise in a credit line to the material. If material is not included in the article's Creative Commons licence and your intended use is not permitted by statutory regulation or exceeds the permitted use, you will need to obtain permission directly from the copyright holder. To view a copy of this licence, visit http://creativeco mmons.org/licenses/by/4.0/. The Creative Commons Public Domain Dedication waiver (http://creativecommons.org/publicdomain/ zero/1.0/) applies to the data made available in this article, unless otherwise stated in a credit line to the data. 
excess reliance on phenotype-based triatomine-bug taxonomy, and confirm the Triatominae as an informative model system for the study of phenotypic change under ecological pressure.

Keywords: Triatominae, Rhodnius, Chagas disease, Systematics, Morphometrics, Genetics

\section{Introduction}

Triatomine bugs transmit Trypanosoma cruzi among the mammalian hosts they associate with in shared microhabitats $[1,2]$. Bugs that occur in human-made habitats may transmit the parasite to people, fueling the spread of Chagas disease $[1,3]$. It has been proposed that occupation of new microhabitats may trigger selection for distinct phenotypic variants in these blood-sucking bugs [4]. Over the last few decades, molecular studies have identified examples of phenotypic convergence or divergence at several systematic levels [5-9]. Perhaps most remarkably, molecular phylogenetic analyses suggest that none of the three genera to which the main Chagas disease vectors belong (Triatoma, Panstrongylus and Rhodnius), which are all defined after morphological characters [1], is monophyletic [8-14]. A few named species have been shown to be phenotypic variants of another species [8]; for example, Triatoma melanosoma is now regarded as a $T$. infestans chromatic variant $[15,16]$. Conversely, some named species have been shown to include several cryptic taxa [8]; for example, Rhodnius robustus (s.l.) is composed of at least five distinct lineages, two of which have been formally described as $R$. montenegrensis and $R$. marabaensis [8,17-21]. Further examples of phenotype/ genotype mismatch are reviewed in [8].

The sometimes striking variation of triatomine-bug phenotypes has been attributed to a propensity of morphological characters to change in response to changing habitat features [2, 4, 22]. Thus, within-species divergence may be driven by habitat shifts (e.g., wild to domestic) involving subsets of genetically homogeneous populations [4], and the use of similar habitats by genetically distinct populations may result in convergence or in the retention of ancestral phenotypes $[2,4,23]$. When using morphological characters only, therefore, taxonomists are in peril of describing spurious species or overlooking cryptic taxa [8]. Despite the practical importance of accurate taxonomic judgment when the organisms of interest transmit a life-threatening parasite, the degree, direction and underlying causes of phenotypic change and diversity in triatomines remain obscure.

In this paper, we combine a detailed phenotypic characterization, qualitative and quantitative, with mitochondrial cytochrome $b$ gene $(c y t b)$ and nuclear ribosomal second internal transcribed spacer (ITS2) DNA sequence analyses to study Rhodnius ecuadoriensis populations spanning most of the geographic/ecological range of the species (Fig. 1). Rhodnius ecuadoriensis is a major vector of T. cruzi in western Ecuador and northwestern Peru [24-26]. In Ecuador, northern wild populations are primarily associated with the endemic Phytelephas aequatorialis palm in both Andean wet forests and lowland dry forests; in the dry inter-Andean valleys of southwestern Ecuador, where native palms are rare or absent, wild $R$. ecuadoriensis seem to primarily associate with arboreal squirrel nests [1, 2, 27-33]. The natural habitats of Peruvian populations remain unclear, with a few records suggesting association with vertebrate nests/refuges in hollow trees and perhaps cacti $[2,26,27,34]$. In addition, some $R$. ecuadoriensis populations have adapted to live in and around houses in coastal Ecuador and, especially, in the dry valleys of southwestern Ecuador and northwestern Peru-where the bugs contribute to endemic Chagas disease [24-26, 35-39]. In coastal and in southwestern Ecuador, bugs from wild and human-made habitats have overlapping phenotypes [40] and identical or nearly identical mitochondrial cytb haplotypes [41]; this, together with frequent, rapid reinfestation of insecticide-treated dwellings [36, 42] and preliminary microsatellite data [41, 43], indicates that wild and non-wild $R$. ecuadoriensis populations are locally highly interconnected. Our comparative phenotypic and genetic analyses cover most of the known geographic and ecological diversity in $R$. ecuadoriensis; they reveal that phenotypic divergence and convergence can both occur within a single nominal triatomine-bug species, and suggest that microhabitat adaptations likely play a crucial role in this phenomenon.

\section{Methods}

\section{Origins of bugs and qualitative phenotype assessment}

We compared $R$. ecuadoriensis type specimens from La Toma, Catamayo, Loja Province, Ecuador (Laboratório Nacional e Internacional de Referência em Taxonomia de Triatomíneos [LNIRTT], Fiocruz, Brazil; [44]) and canonical descriptions of the species $[1,45]$ with fieldcollected Ecuadorian bugs, including (i) northern bugs from $\mathrm{Ph}$. aequatorialis palms of Santo Domingo de los Tsáchilas Province (Andean wet forests; “Tsáchilas" hereafter) and Manabí Province (lowland dry forests), and (ii) primarily nest-dwelling southern-Andean bugs caught in/ around houses in El Oro (Puyango river basin) and Loja 


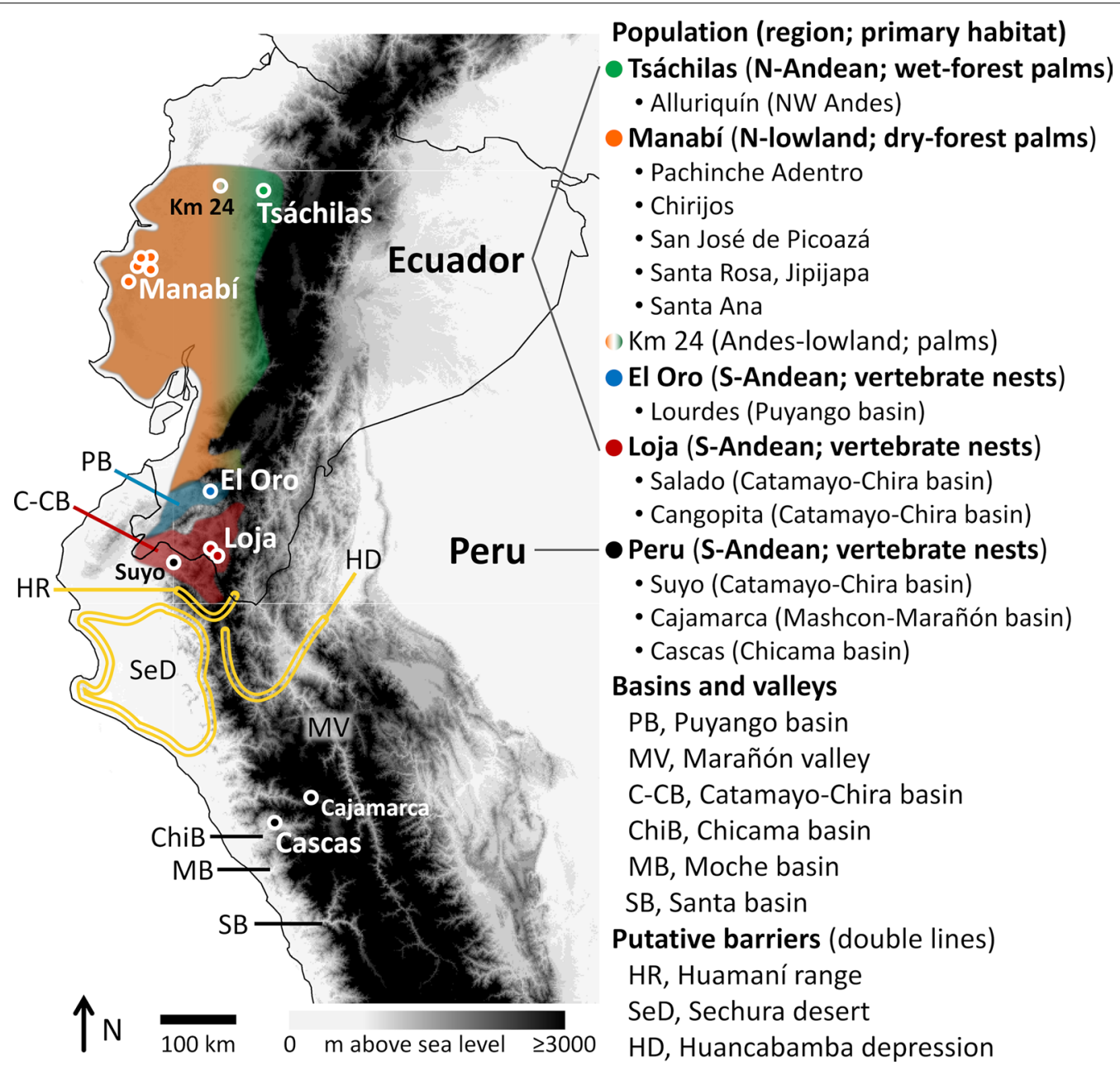

Fig. 1 Sampling of Rhodnius ecuadoriensis populations. The map shows the approximate known distribution of R. ecuadoriensis in Ecuador, including the western-Andean wet premontane (or "cloud") forests (green), the drier coastal lowlands (orange), the Andes-lowland transition and the southern, dry inter-Andean valleys associated with the Puyango (PB; blue) and Catamayo-Chira basins (C-CB; red). The approximate geographic location of each study population in Santo Domingo de los Tsáchilas, Manabí, El Oro, Loja and Peru is indicated by green, orange, blue, red and black circles, respectively; just one specimen was available from both Suyo and Cajamarca. Most Peruvian material came from Cascas, in the middle-upper Chicama basin (ChiB), La Libertad. Putative barriers to past or current bug dispersal are indicated with gold-colored double lines: the Huamaní range $(H R)$, which closes off the $\mathrm{C}-\mathrm{CB}$ to the south; the Sechura desert $(\mathrm{SeD})$ on the northern Peruvian coastal plains; and the Huancabamba depression $(H D)$. The semiarid Santa river basin (SB) appears to mark the southern limit of R. ecuadoriensis' range. Rhodnius ecuadoriensis also occurs along the middle-upper (inter-Andean) stretches of the Marañón river valley (MV. See details in Additional file 1:Table S1 and main text

(Catamayo-Chira basin) provinces (Fig. 1). CAC Cuba (University of Brasília, Brazil) supplied additional fieldcaught southern-Andean Peruvian bugs from dwellings of Suyo (department of Piura, Catamayo-Chira basin) and Cascas (department of La Libertad, Chicama basin) [39] (Fig. 1). Finally, bugs from two colonies founded with material collected from, respectively, Ph. aequatorialis palms of Manabí and houses of northwestern Peru (department of Cajamarca, Mashcon-Marañón basin) were supplied by J Jurberg (LNIRTT) (see details in Additional file 1: Table S1). Using these specimens, which we note were fresh at the time of processing, we conducted a detailed review of external morphological and chromatic characters central to classical triatomine-bug taxonomy $[1,45]$ and placed the results in the broader context of what we know about the systematics, biogeography and ecology of $R$. ecuadoriensis [1, 2, 8, 18, 25-36, 38-43]. In particular, we emphasize that northern populations primarily exploit palm-crown microhabitats just like most Rhodnius species do [2, 29], whereas wild southernAndean populations are primarily associated with vertebrate tree-nests in dry ecoregions where palms are either 
rare or absent $[2,8,25-34]$. Our sampling thus captures this key ecological difference, and we will hereafter refer to northern Tsáchilas and Manabí bugs as "primarily palm-dwelling" and to southern-Andean El Oro, Loja and Peru bugs as "primarily nest-dwelling" [2]. We note again that a growing body of evidence suggests that wild and non-wild $R$. ecuadoriensis populations are locally highly cohesive [36, 40-43].

\section{Traditional morphometrics-heads}

We used 79 adult $R$. ecuadoriensis specimens for this part of the study; 77 were fresh bugs and two were collection bugs (see specimen details in Additional file 1: Table S1). We measured lateral- and dorsal-view, calibrated head images (Fig. 2) and calculated descriptive statistics for the whole sample and for ecological populations (primarily palm-dwelling $v s$ primarily nest-dwelling) and geographic groups. To assess head-size variation, we estimated population means (over all head measurements) and likelihood-profile 95\% confidence intervals (CIs) by fitting Gaussian generalized linear models (identity link-function, no intercept) using package lme4 1.1-21 [46] in R 3.6.3 [47]. For multivariate analyses, log-transformed data were centered by row to remove isometric size; the resulting "log-shape ratios" $[48,49]$ were used as input for principal component analysis (PCA) on covariances. The derived principal components (PCs or "shape variables") were submitted to canonical variate analysis (CVA). We assessed the overall significance of multivariate CVA using Wilks' $\lambda$ statistic [50]. We computed canonical vectors (CVs) and used the first two CVs to plot the position of each specimen on the shape discriminant space; "convex hulls" enclosing all points within each group were overlaid on the plots. Finally, a space of size-free shape variables was constructed by explicitly removing size (represented by $\mathrm{PC} 1$ ) from the measurements; for this, residuals of linear regression of PC1 on each measurement were used as new variables for sizefree CVA [51-53]. The derived CV1 and CV2 were plotted as described above. Different parts of these analyses were conducted using R 3.6.3 [47], JMP 9.0 (SAS Institute, Cary, NC, USA), and NTSYS 2.10y [54].

\section{Geometric morphometrics - heads and forewings}

Dorsal-head and forewing images of, respectively, 84 and 82 adult bugs (all fresh except for 1 collection bug; see details in Additional file 1: Table S1) were digitized for a series of two-dimensional coordinates (Fig. 2) using tpsDig 1.18 [55]. Raw coordinates were subjected to the Procrustes superimposition algorithm [56] and thin plate spline (TPS) analysis using tpsRelw 1.18 [57]. We used TPS to compute "partial warps" with affine (global stretching) and non-affine (non-linear localized distortions or "shape changes") components. PCA of partial warps yielded shape components ("relative warps"), which were subjected to CVA as described above. We also computed: (i) "centroid sizes" as overall measures of head and forewing size; and (ii) Mahalanobis distances between population pairs [22, 40, 49].

\section{Molecular analyses}

We used $72 R$. ecuadoriensis fresh specimens for mitochondrial DNA analyses and a subset of 17 bugs for nuclear DNA analyses (see details in Additional file 1: Table S1); R. colombiensis, $R$. pallescens and $R$. pictipes were used as outgroup taxa. We extracted DNA from bug legs using DNeasy kits (Qiagen, Valencia, CA). A 663-bp fragment of the mitochondrial cytochrome $b$ gene $(c y t b)$ and the complete nuclear ribosomal ITS2 (707-715 bp) were amplified, purified and Sanger-sequenced as previously described $[9,11,17]$. We visually inspected the chromatograms of forward and reverse DNA strands with SeqMan Lasergene 7.0 (DNASTAR Inc., Madison, WI, USA); in inspecting ITS2 chromatograms, we particularly checked for the "double signal" typical of paralogous pseudogene sequences [58, 59]. We aligned consensus and outgroup sequences in MAFFT 7.0 [60], using the L-INS-i algorithm and further manual finetuning. We then computed descriptive statistics using MEGA X [61].

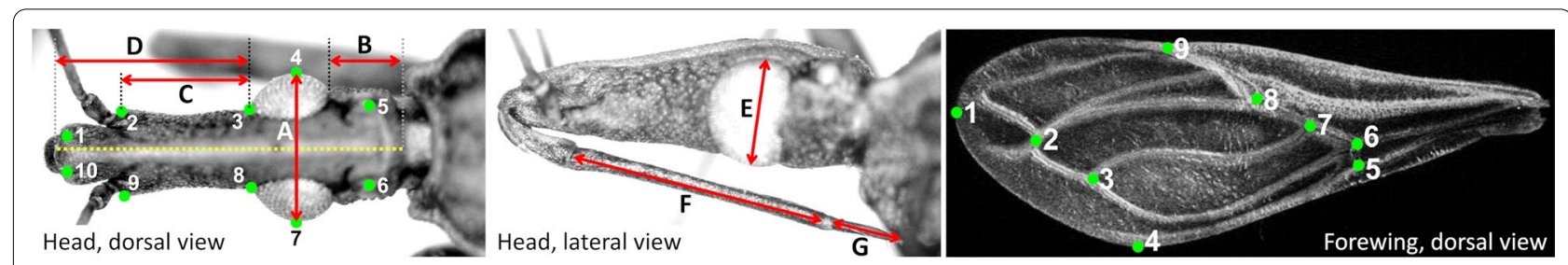

Fig. 2 Measurements and landmarks used in the morphometric analyses. Head measurements were used for traditional morphometrics: $A$ Maximum width across the eyes, $B$ postocular distance (posterior eye limit to head/neck limit), $C$ length of antenniferous tubercle (anterior eye limit to distal tip of tubercle), $D$ anteocular distance (anterior eye limit to base of anteclypeus), $E$ maximum diameter of the eye, $F$ length of second rostral segment, $G$ length of third rostral segment. The yellow dotted line indicates head length, which we used, together with $A$, to compute head length:width ratios. Green dots show the landmarks used for geometric morphometrics 
The best-fitting model of base substitution for each marker was selected using the Bayesian information criterion (BIC) in bModelTest 1.2 [62]. We used the "BEAST 0.15 package of the BEAST 2.6 platform [63, 64] to reconstruct Bayesian locus-specific phylogenetic trees and multispecies-coalescent species trees [63], with three independent runs $\left(5 \times 10^{7}\right.$ generations) for each analysis. For locus-specific trees, we used the coalescent model and sampled parameters every 10,000 generations; for species trees, we used the Yule model of speciation and sampled parameters every 50,000 generations. We evaluated (using Tracer 1.7 [65]) parameter convergence and proper mixing by inspecting individual chains and by checking that effective sample sizes (ESSs) were sufficiently large; in our case, all ESSs were $\geq 10^{4}$. As a complement to phylogenetic analyses, we used pegas 0.14 [66] to build haplotype networks (infinite-sites model, Hamming distances) for both loci.

It has been suggested, based on limited mitochondrial DNA data, that $R$. ecuadoriensis may comprise two distinct lineages: one primarily from Ecuador ("group I") and the other primarily from Peru ("group II") $[6,18]$. We set out to formally assess the data support for this "twolineage" hypothesis $\left(\mathrm{H}_{1}\right)$, relative to the null hypothesis of a single lineage $\left(\mathrm{H}_{0}\right)$, by computing and comparing the marginal likelihood $(\mathrm{mL})$ and posterior probability of each hypothesis $[67,68]$. To do this, we first used our $c y t b$ and ITS2 sequence data to estimate species trees under both $\mathrm{H}_{1}$ (with each $R$. ecuadoriensis sequence assigned to a pre-defined, geography-based group, either "Ecuador" or "Peru"; Fig. 1) and $\mathrm{H}_{0}$ (with all R. ecuadoriensis sequences assigned to a single group). We then estimated the $\mathrm{mL}$ of each species tree using two approaches: (i) nested sampling $[68,69]$, as implemented in the NS 1.1 package [69] of BEAST 2.6 [63], with $5 \times 10^{6}$ Markov chain Monte Carlo (MCMC) generations, $2 \times 10^{4}$ subchain length and five active points; and (ii) path sampling (also known as "thermodynamic integration") [68, 70], as implemented in the Model Selection 1.0.1 package of BEAST 2.6 [64], with a pre-burn-in of $2 \times 10^{5}$ MCMC iterations followed by 90 steps of $2 \times 10^{6}$ iterations $(50 \%$ burn-in) and each step repeated 500 times. Using the hypothesis-specific $\log -\mathrm{mL}$ values, we finally computed $\log$-Bayes factors $(B F)$ as $\log -\mathrm{BF}=\log -\mathrm{mL}\left(\mathrm{H}_{1}\right)-\log$ $\mathrm{mL}\left(\mathrm{H}_{0}\right)$ [67]. For two hypotheses with equal prior probabilities, $\operatorname{Pr}\left(\mathrm{H}_{1}\right)=\operatorname{Pr}\left(\mathrm{H}_{0}\right)=0.5$, the Bayesian posterior probability (BPP), given the data $(D)$, of $\mathrm{H}_{1}$ is $\operatorname{Pr}\left(\mathrm{H}_{1} \mid D\right)$ $=\mathrm{BF} /(1+\mathrm{BF})$, and the posterior probability of $\mathrm{H}_{0}$ is therefore $\operatorname{Pr}\left(\mathrm{H}_{0} \mid D\right)=1-\operatorname{Pr}\left(\mathrm{H}_{1} \mid D\right)$. Kass and Raftery [67] proposed a set of rules of thumb, derived from those first suggested by Jeffreys [71], to grade the evidence in favor of $\mathrm{H}_{1}$ : the evidence is weak when $1 \leq \mathrm{BF}<3$; positive when $3 \leq \mathrm{BF}<20$; strong when $20 \leq \mathrm{BF}<150$; and very strong when $\mathrm{BF} \geq 150$. In a two-hypotheses context like ours, this means that evidence in favor of $\mathrm{H}_{1}$ (or against $\mathrm{H}_{0}$ ) would be deemed very strong only if examination of the data changed the 1:1 prior odds $\left(\operatorname{Pr}\left(\mathrm{H}_{1}\right)=\operatorname{Pr}\left(\mathrm{H}_{0}\right)=\right.$ $0.5)$ to a posterior odds of at least $150: 1$, so that $\operatorname{Pr}\left(\mathrm{H}_{1} \mid D\right)$ $\geq 0.993$ and $\operatorname{Pr}\left(\mathrm{H}_{0} \mid D\right) \leq 0.007$.

We note that the $R$. ecuadoriensis cytb sequences studied by Villacis et al. [41, 72] were not publicly available at the time of writing this report, when the National Center for Biotechnology Information (NCBI) GenBank held five such sequences. Sequence AF045715 [73] is only 399 bp, and sequences KC543508-KC543510 [74] are identical to some of the haplotypes we found (details below). Finally, KC543507 from a Manabí bug [74] differs at three positions from two of our Manabí haplotypes; one of those substitutions, however, yields a thymine at a second codon position (position 233 in Additional file 2: Alignment S1) where cytosine is conserved across all cytb sequences from Rhodnius species we have been able to examine (e.g., see [8]). This singular non-synonymous substitution (valine instead of alanine as in all other Rhodnius except $R$. prolixus and some $R$. robustus, which have threonine) suggests that KC543507 [74] may contain base-call errors, and we therefore excluded this particular sequence from further consideration. Our analyses, in sum, are based on all reliable $R$. ecuadoriensis sequences of reasonable length (here, $663 \mathrm{bp}$ ) that, as far as we know, are currently available for the two loci we investigated.

\section{Results}

\section{Qualitative phenotypic assessment}

All southern-Andean, primarily nest-dwelling bugs from El Oro, Loja and Peru had comparable, typical phenotypes $[1,45]$, whereas northern-Andean specimens from wet-forest palms (Tsáchilas) were very large and dark bugs with long, slender heads; northern-lowland bugs from dry-forest palms (Manabí) had intermediate phenotypes (Figs. 3, 4). Below and in Table 1 we present summary descriptions of these diverse putative $R$. есиadoriensis phenotypes (or "forms"); detailed descriptions are provided in Additional file 3: Text S1.

\section{Typical forms: primarily nest-dwelling southern-Andean bugs} Primarily nest-dwelling bugs caught in/around houses in southwestern Ecuador (El Oro, Puyango basin; and Loja, Catamayo-Chira basin) were virtually identical to the type material-very small triatomines, light brownyellowish with dark-brown stripes and irregular markings on the body and appendages $[1,45]$ (Fig. 3). Peruvian bugs were collected in/around houses of the dry middleupper Chicama basin (Cascas, La Libertad, approx. 350 


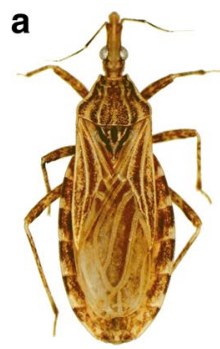

e

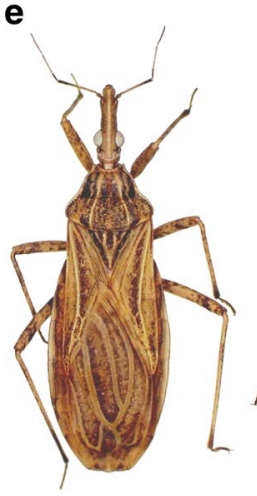

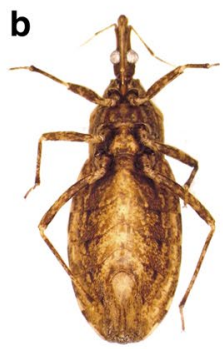

$\mathbf{f}$

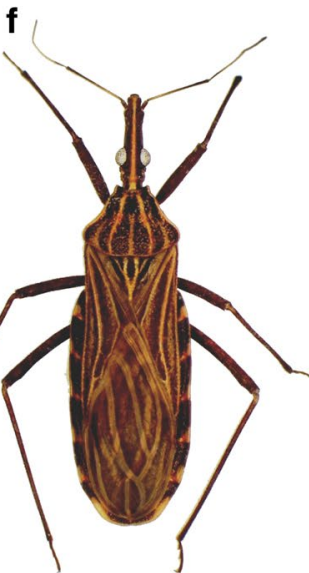

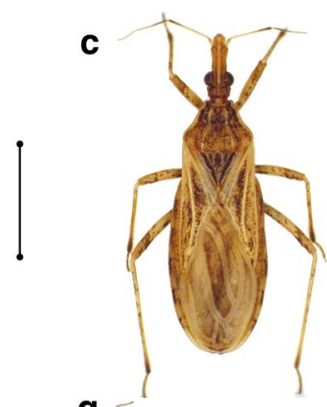

g

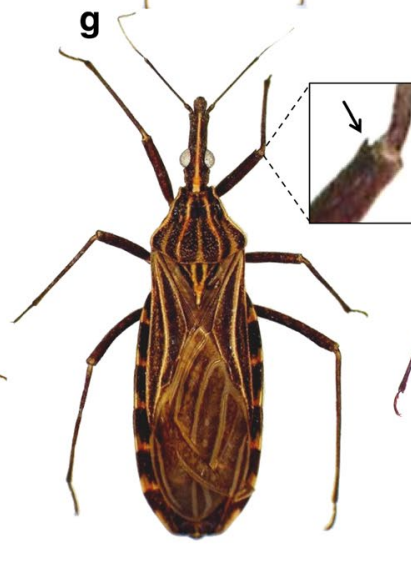

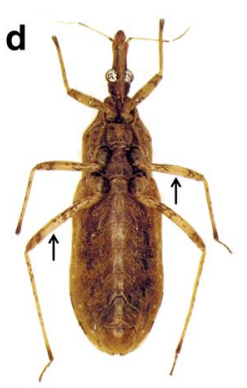

h

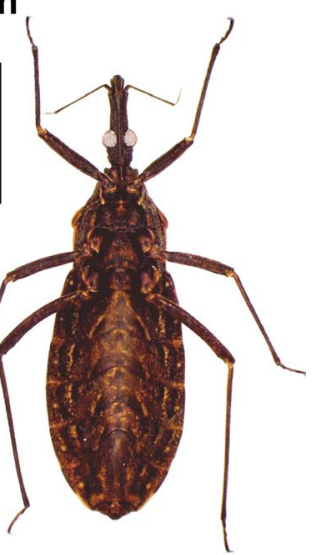

Fig. 3 Phenotypic diversity in Rhodnius ecuadoriensis. a-d Southern-Andean populations (primarily from vertebrate tree-nests but often found in/around houses): Loja female, dorsal (a) and ventral (b) views; and Peru male, dorsal (c) and ventral (d) views; the arrows in $\mathbf{d}$ indicate the lighter central area of femora (see text). e-h Northern populations (primarily from Phytelephas aequatorialis palms): northern-lowland Manabí female, dorsal view (e), northern-Andean Tsáchilas male, dorsal view (f), northern-Andean Tsáchilas female, dorsal view (g; the inset highlights the well-developed denticle in the distal tip of the fore femora), northern-Andean Tsáchilas female, ventral view (h). Scale bar: approx. 5 mm

$\mathrm{km}$ south of our fieldwork sites in Loja), except for one specimen collected in Suyo, Piura, within the CatamayoChira basin (Fig. 1; Additional file 1: Table S1). The overall aspect of Peruvian bugs largely matches that of type material (Fig. 3). However, Chicama-basin bugs are noticeably lighter-colored than southern-Andean Ecuadorian bugs; this is more evident on the legs, where the dark mottled pattern is limited to small clusters of dots and stripes on the basal and distal thirds of femora and tibiae (Fig. 3). The posterior lobe of the pronotum is also lighter than in Ecuadorian material, and Chicama-basin bugs are more slender than the typical specimens from El Oro-Loja. Similar to type material, the heads of these Peruvian specimens are noticeably short and stout (Fig. 3; see also Additional file 3: Text S1).

\section{Intermediate forms: primarily palm-dwelling northern-lowland bugs}

Phytelephas aequatorialis palms often harbor wild $R$. ecuadoriensis populations in the central coastal province of Manabí, Ecuador [2, 28, 29, 31]. The overall aspect and coloration of these lowland, primarily palm-dwelling bugs largely match those of typical $R$. ecuadoriensis, but

\section{Southern-Andean (Loja; squirrel nests, houses)}

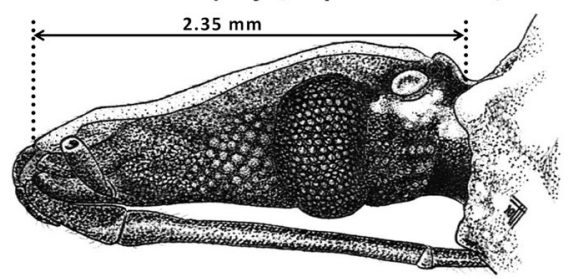

Northern-Andean (Tsáchilas; wet-forest palms)

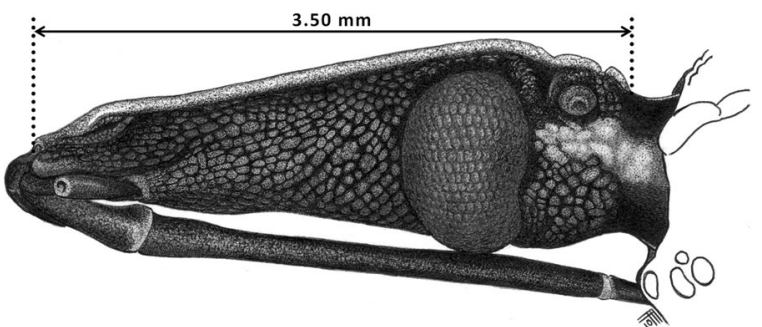

Fig. 4 Heads (lateral view) of southern-Andean and northern-Andean Rhodnius ecuadoriensis: typical bugs primarily from vertebrate tree-nests (Loja) vs atypical bugs primarily from Andean Phytelephas aequatorialis palms (Tsáchilas). Note the striking divergence, which clearly falls within the range of what are normally considered interspecies differences in the Triatominae [1]. Drawings by FA-F 


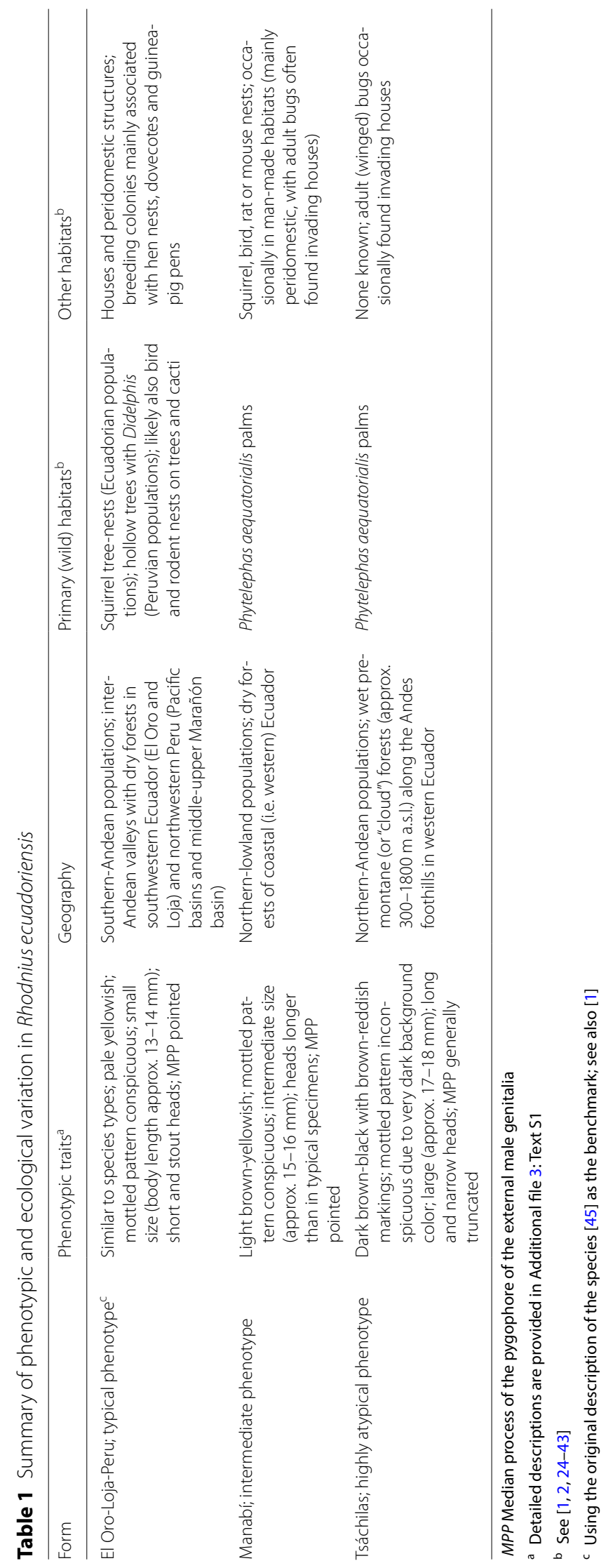



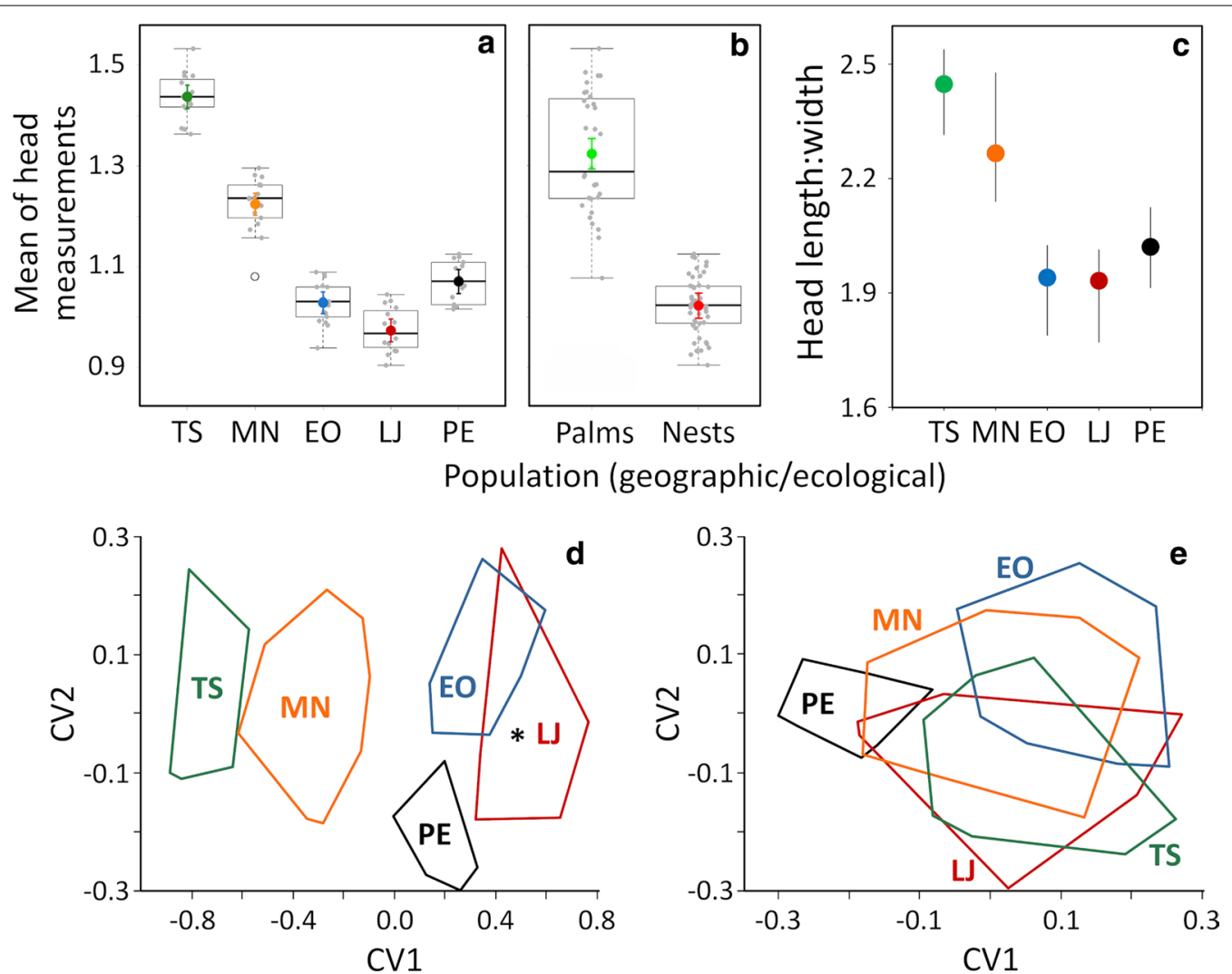

Fig. 5 Traditional morphometrics of Rhodnius ecuadoriensis heads. Upper panels a-c: head size divergence among geographic (a) and ecological (b) populations. Population codes: TS Tsáchilas (dark green), MN Manabí (orange), EO El Oro (blue), LJ Loja (dark red), PE Peru (black). The primary habitat of each population is indicated in b: "Palms" for the the northern TS + MN populations (light green) and "Nests" for the southern-Andean $\mathrm{EO}+\mathrm{L}+\mathrm{PE}$ populations (bright red). Box plots (a, b) show medians (thick horizontal lines), quartiles (boxes) and values that fall within 1.5-fold the inter-quartile range (whiskers); note a single small-sized outlier (empty circle in a) in the MN population. Colored circles and error bars show population means and 95\% confidence intervals. c Relation between head length (yellow dotted line in Fig. 2) and width (measurement "A" in Fig. 2), as the mean and range of raw length:width values; note the elongated heads of TS and MN bugs and the shorter, stouter heads of $L, E O$ and PE bugs. $\mathbf{d}$, e Size and shape divergence among geographic populations. $\mathbf{d}$ Isometry-free canonical discriminant analysis of linear head measurements; the asterisk indicates the position of a specimen from Suyo (Catamayo-Chira basin, Peru) in discriminant space. e Size-free canonical discriminant analysis on the residuals of linear regression of the first principal component on each head measurement. CV Canonical vector. See text for methodological details

Manabí bugs have larger bodies and longer, more slender heads (Fig. 3; see Additional file 3: Text S1).

\section{Atypical forms: primarily palm-dwelling northern-Andean bugs}

In 1998, a male Rhodnius specimen was collected at light near Alluriquín, Santo Domingo de los Tsáchilas, approximately $900 \mathrm{~m}$ a.s.l. on the central-western Ecuadorian Andes foothills (Fig. 1). This wet premontane forest site is within the range of $R$. ecuadoriensis, which is not shared by any other known Rhodnius species [8, 18, 25, 75], but the morphology and coloration of the specimen differed strikingly from those of $R$. ecuadoriensis type material (Table 1). Field surveys in Alluriquín yielded abundant material from $\mathrm{Ph}$. aequatorialis palms [28, 76]. These bugs are much larger and darker, and have much longer heads, than typical $R$. ecuadoriensis (Table 1; Figs. 3, 4; Additional file 3: Text S1); they are, however, smaller than the closely related, light-colored $R$. pallescens and $R$. colombiensis [1, 77] (Additional file 4: Figure S1). Nakedeye phenotype differences between northern-Andean bugs and typical southern-Andean specimens are in the range customarily associated with distinct species in the Triatominae-and tend towards the "highly divergent" extreme of that range if we consider closely related species within the genus Rhodnius [1, 5, 8, 17-19] (Table 1; Figs. 3, 4; see also Additional file 3: Text S1 and Additional file 4: Figure S1). 


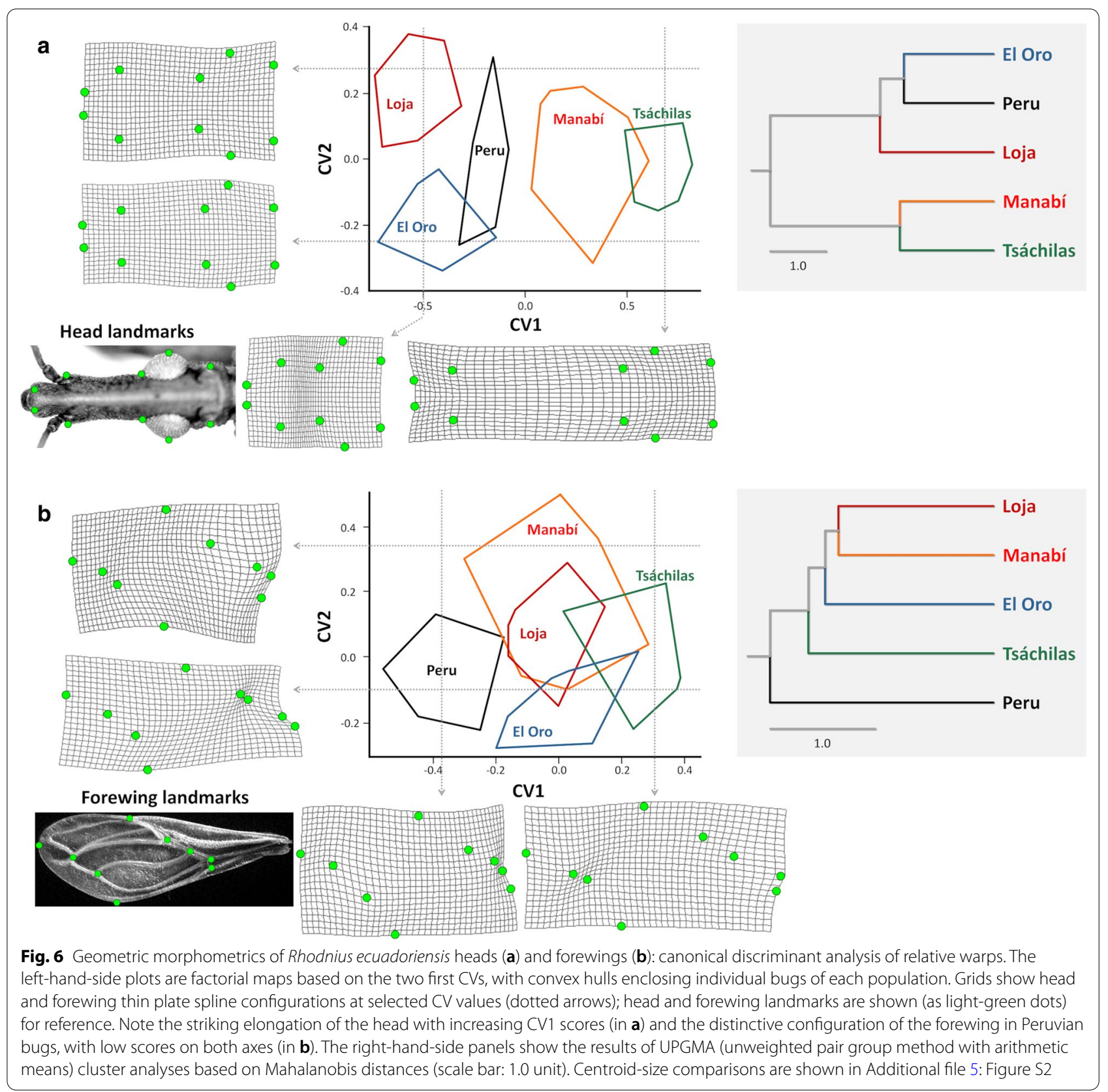

\section{Traditional morphometrics-heads}

Northern-Andean bugs from Tsáchilas palms clearly had the largest heads in our sample; northern-lowland bugs from Manabí palms were smaller than Tsáchilas specimens but larger than southern-Andean bugsamong which those from Loja had the smallest heads and those from Peru were larger on average (Fig. 5a). Overall, the heads of primarily palm-dwelling bugs were larger (Fig. 5b) and more elongated (Fig. 5c) than those of primarily nest-dwelling bugs. CVA confirmed amonggroup differences (Wilks' $\lambda=0.024 ; P<0.0001$ ), with a negative correlation between CV1 scores and head size; again, discrimination between primarily palm-dwelling northern populations and primarily nest-dwelling southern-Andean populations was complete (Fig. 5d). Some overlapping occurred between El Oro and Loja, and a single Peruvian specimen was firmly nested within the Loja cluster (asterisk in Fig. 5d). This specimen was collected in Suyo, approximately $20-50 \mathrm{~km}$ from our fieldwork sites in Loja and also within the Catamayo-Chira basin (Fig. 1). When size effects were explicitly removed (see "Methods"), all Ecuadorian populations (plus the 


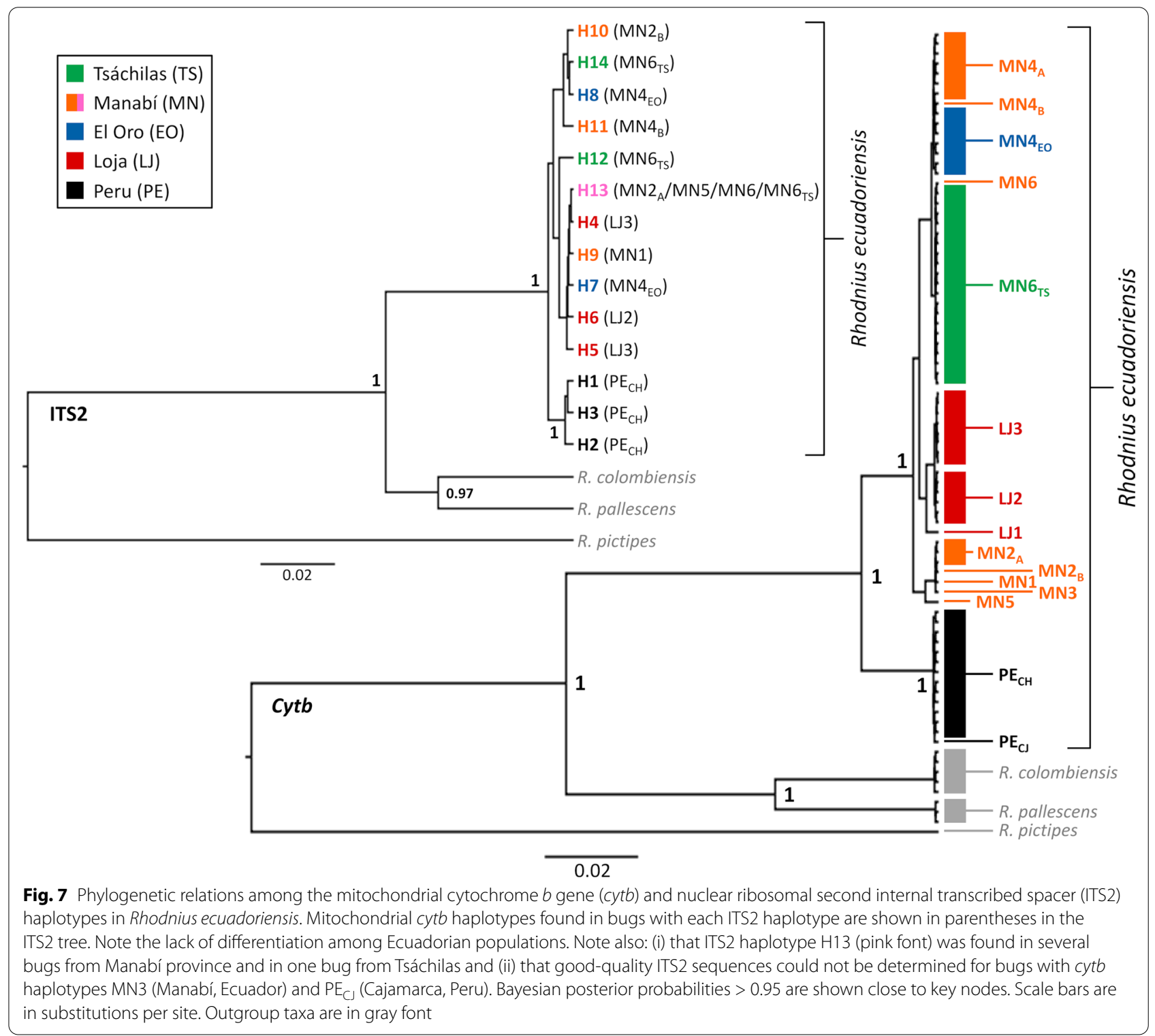

Suyo bug) were remarkably similar to one another, with bugs from Peru appearing as the most distinct (Fig. 5e).

\section{Geometric morphometrics-heads and forewings}

Geometric head-shape analyses (Wilks' $\lambda=0.051 ; P$ $<0.0001)$ confirmed the striking contrast between the large, elongated heads of northern, primarily palm-dwelling bugs (and, in particular, northern-Andean bugs from Tsáchilas) and the small, short-and-stout heads of primarily nest-dwelling southern-Andean bugs (Fig. 6a; see also Figs. 4, 5c). Centroid-size comparisons (Additional file 5: Figure S2) closely mirrored the results of the headsize analysis shown in Fig. 5a. The patterns revealed by CVA of forewing-shape components (Fig. 6b; Wilks' $\lambda=$
0.016; $P<0.0001$ ) were comparable to those revealed by size-free traditional head morphometrics (see Fig. 5e), although the divergence of Peruvian bugs was clearer against a backdrop of broad similarity among Ecuadorian populations (Fig. 6b). Thin plate splines and CV1 scores suggested that most Tsáchilas, some Manabí, and a few El Oro bugs had more elongated forewings, particularly in comparison with Peruvian material; most bugs from El Oro and Loja, as well as some Manabí specimens, were somewhat intermediate (Fig. 6b). Forewing centroid-size values were similar across primarily nestdwelling southern-Andean populations, much larger in northern-Andean bugs, and again intermediate in 


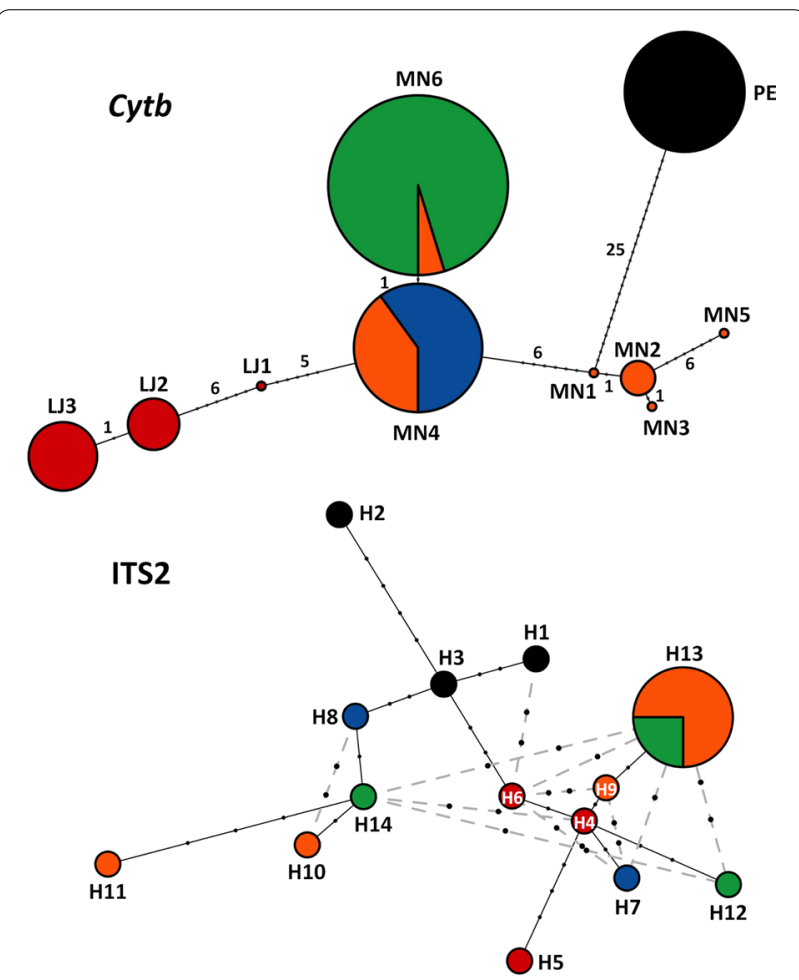

Fig. 8 Networks of mitochondrial cytb and nuclear ITS2 haplotypes in Rhodnius ecuadoriensis. Each circle represents a haplotype, with circle size proportional to haplotype frequency. Mutational steps are represented by black dots, with numbers given for the smaller-sized dots of the cytb network. Alternative connections between

haplotypes (represented by gray-broken edges) were only inferred for the ITS2 network. Color codes are as in Figs. 1, 5, 6, and 7

northern-lowland Manabí bugs (Additional file 5: Figure S2).

\section{Molecular analyses 1-mitochondrial DNA}

We found ten $c y t b$ haplotypes, some recovered from different collection sites, in our R. ecuadoriensis samples (see Additional file 1: Table S1; Figs. 7, 8; and below). All 663-bp sequences comprised an open reading frame with no stop codons or any other signs of pseudogene sequences. The $R$. ecuadoriensis cytb alignment had 42 variable sites (6.3\%); 36 were in third codon positions, five in first codon positions, and one was in a second codon position. There were two non-synonymous point mutations in a single codon of the only haplotype (PE) found in all 13 Peruvian bugs-with ACT (threonine) instead of GTT (valine). One Manabí haplotype (MN5) also had a first codon position non-silent substitutionATT (isoleucine) instead of CTT (leucine) (see Additional file 2: Alignment S1; sequences were deposited in GenBank under accession codes MT497021-MT497035 for R. ecuadoriensis and MT497036-MT497038 for outgroup taxa).
We isolated six cytb haplotypes (MN1-MN6) from northern-lowland Manabí bugs (Additional file 1: Table S1). MN1, MN3 and MN5 were found in one specimen each. MN2 was detected in bugs from two sites (codes $\mathrm{MN}_{\mathrm{A}}$ and $\mathrm{MN} 2_{\mathrm{B}}$ ); $\mathrm{MN} 2$ is identical to KC543509 from Santa Ana, Manabí [74]. MN4 was also found in bugs from two distinct Manabí sites $\left(\mathrm{MN}_{\mathrm{A}}\right.$ and $\left.\mathrm{MN} 4_{\mathrm{B}}\right)$, as well as in all nine southern-Andean bugs from El Oro $\left(\mathrm{MN} 4_{\mathrm{EO}}\right)$, including those collected in two different sites and in different years; MN4 is identical to KC543510, also from Santa Ana, Manabí [74]. MN6 was found in one bug from Manabí and in the 20 northern-Andean specimens from Tsáchilas palms $\left(\mathrm{MN}_{\mathrm{TS}}\right)$. MN4 and MN6 differ by a single, third codon position $\mathrm{C} / \mathrm{T}$ transition. We isolated three unique haplotypes (LJ1, LJ2 and LJ3) from the 15 southern-Andean Loja bugs (Additional file 1: Table S1); LJ2 is identical to KC543508 from Quilanga, Loja, in the Catamayo-Chira basin [74]. Finally, 13 Peruvian bugs from at least three dwellings of the middle-upper Chicama basin also yielded a single, unique haplotype $\left(\mathrm{PE}_{\mathrm{CH}}\right)$. One specimen from the reference $R$. ecuadoriensis colony at LNIRTT, founded in 1979 with bugs from Cajamarca, had the same haplotype (coded $\mathrm{PE}_{\mathrm{C}}$ ) (Additional file 1: Table S1). Haplotype PE was the most distinct among all the $R$. ecuadoriensis cytb sequences we studied; it was separated by 25 nucleotide substitutions from the closest Ecuadorian haplotype (MN1; see Figs. 7, 8; Additional file 2: Alignment S1; and below).

Overall, uncorrected $c y t b$ nucleotide diversity was $\pi$ $=0.0179 \pm 0.0029$ standard error (SE) (SEs estimated with 1000 bootstrap pseudo-replicates). Mean Kimura 2-parameter $(\mathrm{K} 2 \mathrm{p})$ distances were $0.0185 \pm 0.0031 \mathrm{SE}$ for the 72-sequence $c y t b$ alignment and $0.0184 \pm 0.0029$ $\mathrm{SE}$ for the ten-haplotype dataset. K2p sequence divergence was substantially lower among Ecuadorian haplotypes (0.0015-0.01995) than between any of these and PE (0.03904-0.04894). Mean K2p distance between the primarily palm-dwelling northern-Andean (Tsáchilas) and northern-lowland (Manabí) populations was low $(0.0070 \pm 0.0023 \mathrm{SE})$, and much lower than distances between these two populations and the primarily nest-dwelling southern-Andean bugs $(0.0210$ for Tsáchilas and 0.0222 for Manabí; both $\pm 0.0037 \mathrm{SE}$ ). These larger distances were driven by the clearly divergent Peruvian haplotypes; when these were placed in a separate group, K2p distances between Ecuadorian populations were between 0.15 and $1.43 \%$, whereas distances between Ecuadorian and Peruvian populations were all $>4.07 \%$ (Table 2).

The best-fitting model for the $c y t b$ alignment had three substitution rates $(\mathrm{AT}=\mathrm{CG}=\mathrm{GT} ; \mathrm{AG}=\mathrm{CT}$; and $\mathrm{AC})$ with a Gamma shape parameter $(+\Gamma)$ and a proportion of invariable sites $(+I)$. The cytb gene tree shows 
Table 2 Kimura two-parameter distances between pairs of Rhodnius ecuadoriensis populations from across the species' range

\begin{tabular}{|c|c|c|c|c|c|c|}
\hline Marker & Population 1 & Primary habitat & Population 2 & Primary habitat & K2p distance & SE \\
\hline \multirow[t]{10}{*}{ Cytb } & Tsáchilas (N) & Andean palms & Manabí (N) & Lowland palms & 0.00697 & 0.00227 \\
\hline & Tsáchilas (N) & Andean palms & El Oro (S) & Vertebrate nests & 0.00151 & 0.00149 \\
\hline & Tsáchilas (N) & Andean palms & Loja (S) & Vertebrate nests & 0.01283 & 0.00419 \\
\hline & Manabí (N) & Lowland palms & El Oro (S) & Vertebrate nests & 0.00566 & 0.00185 \\
\hline & Manabí (N) & Lowland palms & Loja (S) & Vertebrate nests & 0.01426 & 0.00383 \\
\hline & El Oro (S) & Vertebrate nests & Loja (S) & Vertebrate nests & 0.01129 & 0.00396 \\
\hline & Tsáchilas (N) & Andean palms & Peru (S) & Vertebrate nests & 0.04235 & 0.00823 \\
\hline & Manabí (N) & Lowland palms & Peru (S) & Vertebrate nests & 0.04127 & 0.00782 \\
\hline & El Oro (S) & Vertebrate nests & Peru (S) & Vertebrate nests & 0.04072 & 0.00804 \\
\hline & Loja (S) & Vertebrate nests & Peru (S) & Vertebrate nests & 0.04806 & 0.00868 \\
\hline \multirow[t]{10}{*}{ ITS2 } & Tsáchilas (N) & Andean palms & Manabí (N) & Lowland palms & 0.00308 & 0.00126 \\
\hline & Tsáchilas (N) & Andean palms & El Oro (S) & Vertebrate nests & 0.00331 & 0.00148 \\
\hline & Tsáchilas (N) & Andean palms & Loja (S) & Vertebrate nests & 0.00378 & 0.00152 \\
\hline & Manabí (N) & Lowland palms & El Oro (S) & Vertebrate nests & 0.00402 & 0.00153 \\
\hline & Manabí (N) & Lowland palms & Loja (S) & Vertebrate nests & 0.00402 & 0.00127 \\
\hline & El Oro $(S)$ & Vertebrate nests & Loja (S) & Vertebrate nests & 0.00473 & 0.00168 \\
\hline & Tsáchilas (N) & Andean palms & Peru (S) & Vertebrate nests & 0.00519 & 0.00192 \\
\hline & Manabí (N) & Lowland palms & Peru (S) & Vertebrate nests & 0.00638 & 0.00214 \\
\hline & El Oro (S) & Vertebrate nests & Peru (S) & Vertebrate nests & 0.00614 & 0.00220 \\
\hline & Loja (S) & Vertebrate nests & Peru (S) & Vertebrate nests & 0.00613 & 0.00221 \\
\hline
\end{tabular}

Calculations are based on 72 mitochondrial cytochrome $b$ (cytb) DNA sequences and 17 nuclear ribosomal second internal transcribed spacer (ITS2) DNA sequences from five populations primarily associated with two distinct microhabitats: Phytelephas aequatorialis palms to the north $(\mathrm{N})$ and vertebrate tree-nests to the south $(\mathrm{S})$; see Fig. 1, Table 1 and Additional file 1:Table S1.

K2p Kimura 2-parameter, SE Standard error computed from 1000 bootstrap pseudo-replicates

Table 3 Marginal likelihoods, Bayes factors and hypothesis testing: one versus two independently evolving lineages in Rhodnius ecuadoriensis

\begin{tabular}{|c|c|c|c|c|c|}
\hline Analyses and hypotheses & $\operatorname{Pr}(\mathrm{H})$ & Log-mL & SD & Log-BF & $\operatorname{Pr}(H \mid D)^{a}$ \\
\hline \multicolumn{6}{|l|}{ Nested sampling [69] } \\
\hline $\mathrm{H}_{0}$ : one lineage & 0.5 & -3944.09 & 6.05 & 24.22 & 0 \\
\hline $\mathrm{H}_{1}$ : two lineages ("Ecuador" and "Peru") & 0.5 & -3919.87 & 5.59 & 0 & 1 \\
\hline \multicolumn{6}{|l|}{ Path sampling ${ }^{b}[70]$} \\
\hline $\mathrm{H}_{0}$ : one lineage & 0.5 & -3888.23 & - & 12.94 & $<0.00001$ \\
\hline $\mathrm{H}_{1}$ : two lineages ("Ecuador" and "Peru") & 0.5 & -3875.29 & - & 0 & $>0.99999$ \\
\hline
\end{tabular}

$\operatorname{Pr}(H)$, Prior probability of each alternative hypothesis [here, both hypotheses are equally likely a priori: $\left.\operatorname{Pr}\left(\mathrm{H}_{0}\right)=\operatorname{Pr}\left(\mathrm{H}_{1}\right)=0.5\right], L o g-m L$ natural logarithm of the marginal likelihood, $S D$ standard deviation of the log- $\mathrm{mL}$, Log- $B F$ natural logarithm of the Bayes factor (i.e. the difference in log- $\mathrm{mL}$ between $\mathrm{H}_{1}$ and $\left.\mathrm{H}_{0}\right)$, $\operatorname{Pr}(H \mid D)$ posterior probability of each hypothesis, given the data [here, $\operatorname{Pr}\left(\mathrm{H}_{0} \mid \mathrm{D}\right) \approx 0$ and $\operatorname{Pr}\left(\mathrm{H}_{1} \mid \mathrm{D}\right) \approx 1$ for both analyses]

${ }^{a}$ Estimated under the assumption of equal prior probabilities, as $\operatorname{Pr}\left(\mathrm{H}_{1} \mid \mathrm{D}\right) \approx \mathrm{BF} /(1+\mathrm{BF})$, and $\operatorname{Pr}\left(\mathrm{H}_{0} \mid \mathrm{D}\right)=1-\operatorname{Pr}\left(\mathrm{H}_{1} \mid \mathrm{D}\right)$

b Or"thermodynamic integration"; note that, in the implementation we used, this method does not provide SD estimates for the log-mLs

an unambiguous separation $(\mathrm{BPP}=1.0)$ of the Peruvian haplotype from a monophyletic $(\mathrm{BPP}=1.0)$ Ecuadorian clade. No clear patterns of geographic or ecological segregation are apparent within the Ecuadorian clade, although the three LJ haplotypes unique to Loja bugs (see Fig. 7) cluster together with $\mathrm{BPP} \approx 0.95$. These patterns are also apparent in the $c y t b$ haplotype network shown in Fig. 8.

\section{Molecular analyses 2-nuclear DNA}

We identified 14 unique ITS2 haplotypes (GenBank codes KT267937-KT267950) in our $R$. ecuadoriensis sample, including three $(\mathrm{H} 1-\mathrm{H} 3)$ from Peruvian bugs carrying the $\mathrm{PE}_{\mathrm{CH}}$ cytb haplotype and 11 from Ecuadorian bugs: two from northern-Andean bugs (Tsáchilas, H12 and H14); three from northern-lowland Manabí bugs (H9-H11); one (H13) from several Tsáchilas and 


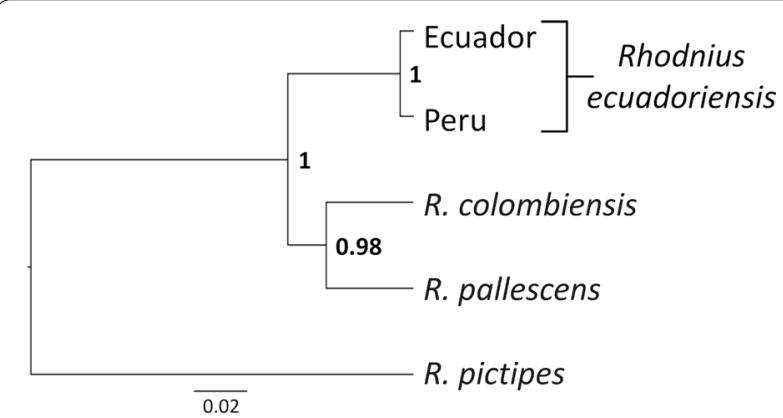

Fig. 9 Multispecies coalescent analysis results: Rhodnius ecuadoriensis species tree estimated using mitochondrial cytb and nuclear ITS2 sequences under the two-lineage hypothesis ("Ecuador" and "Peru"). Maximum clade credibility tree based on 3000 replicate trees; Bayesian posterior probabilities for cladogenetic events are given close to each node. Scale bar is in substitutions/site. Rhodnius colombiensis, R. pallescens and R. pictipes were used as outgroup taxa

Manabí bugs; two from El Oro (H7, H8); and three from Loja (H4-H6) (see Additional file 1: Table S1). All these ITS2 sequences were overall similar to each other (see Table 2; Additional file 6: Alignment S2); there were no signs of pseudogene sequences in the chromatograms. The 720-bp $R$. ecuadoriensis 14-haplotype alignment (Additional file 6: Alignment S2) had 34 variable sites $(4.7 \%)$, of which 18 were mutations (2.5\%) and 16 were indels (2.2\%). Within Ecuador, haplotypes H4 (Loja) and H13 (Manabí and Tsáchilas) differed by a single-nucleotide indel. Using the pairwise deletion option in MEGA X [61], we found an overall, uncorrected nucleotide diversity $\pi=0.0052 \pm 0.0014$ $\mathrm{SE}$; the values were $\pi=0.0046 \pm 0.0014$ SE for Ecuadorian sequences and $\pi=0.0047 \pm 0.0021$ SE for Peruvian haplotypes, with a mean uncorrected between-group distance of $0.0062 \pm 0.0019$ SE. The ITS2-based K2p distance between the primarily palm-dwelling populations (Tsáchilas vs Manabí: $0.0031 \pm 0.0012$ SE) was somewhat smaller than the distances between these and the primarily nest-dwelling southern-Andean populations (0.0042 for Tsáchilas and 0.0049 for Manabí; both $\pm 0.0014 \mathrm{SE})$. Table 2 shows K2p distances between population pairs; while overall low, ITS2-based distances were consistently larger in the comparisons involving Peruvian bugs.

For the ingroup + outgroup alignment (Additional file 7: Alignment S3; outgroup sequences deposited in GenBank under codes KT351069-KT351071), the smallest BIC model of nucleotide substitution included four rates $(\mathrm{AC}=\mathrm{GT} ; \mathrm{AG}=\mathrm{CT}$; $\mathrm{AT}$; and $\mathrm{CG})$, a Gamma shape parameter $(+I)$, and a proportion of invariable sites $(+I)$. Phylogenetic analysis revealed no geographic or ecological structuring among Ecuadorian bugs, but the three
ITS2 haplotypes from Peruvian specimens clustered in a separate clade with BPP $=1.0$ (Fig. 7). This lent support to our $c y t b$ findings and, importantly, indicated that the similarity of mitochondrial DNA sequences across phenotypically and ecologically distinct Ecuadorian bugs (including the highly divergent Tsáchilas specimens; see also Fig. 8) is not due to introgression [78].

\section{Molecular analyses 3-species trees and Bayesian hypothesis testing}

Table 3 summarizes the results of our assessment of the competing hypotheses about the number of independent lineages (one vs two) within $R$. ecuadoriensis. We found that the "two-lineage" hypothesis, $\mathrm{H}_{1}$, has very strong support from our DNA-sequence data, with log$\mathrm{mL}$ estimates consistently larger (by $>24$ and $>12$ units, depending on the estimation procedure) than those of $\mathrm{H}_{0}$ (Table 3). These nested- and path-sampling BF estimates correspond to BPP between 0.999998 and 1.0 in favor of $\mathrm{H}_{1}$; conversely, then, we found that our data provide virtually no support for the "single-lineage" hypothesis (Table 3). Multispecies-coalescent analyses, therefore, substantiated locus-specific and size-free morphometric findings in that the best-supported species tree corresponds to the "two-lineage" hypothesis. This tree (Fig. 9) shows a well-supported $R$. ecuadoriensis clade within which our study specimens consistently segregate into two closely related lineages: (i) the Ecuadorian lineage, including typical southern-Andean bugs primarily from vertebrate tree-nests, atypical northern-Andean bugs primarily from wet-forest palms and intermediate northernlowland bugs primarily from dry-forest palms; and (ii) the Peruvian lineage, including primarily nest-dwelling southern-Andean bugs (with naked-eye phenotypes similar to type material) from the Chicama and MashconMarañón basins (Fig. 9; see also Figs. 1, 3, 4, 5, and 6).

\section{Discussion}

In this report we describe a striking instance of phenotypic divergence and convergence within a single nominal (i.e. named) species of Triatominae, Rhodnius ecuadoriensis. We found: (i) sharp, naked-eye phenotypic divergence of genetically similar Ecuadorian bugs (primarily nest-dwelling southern-Andean populations $v s$ primarily palm-dwelling northern populations-and, within northern palm-dwelling bugs, Andean vs lowland populations); and (ii) marked, naked-eye phenotypic similarity, most likely due to convergence, of primarily nest-dwelling southern-Andean populations (northwestern Peru $v s$ southwestern Ecuador) whose distinct DNA 


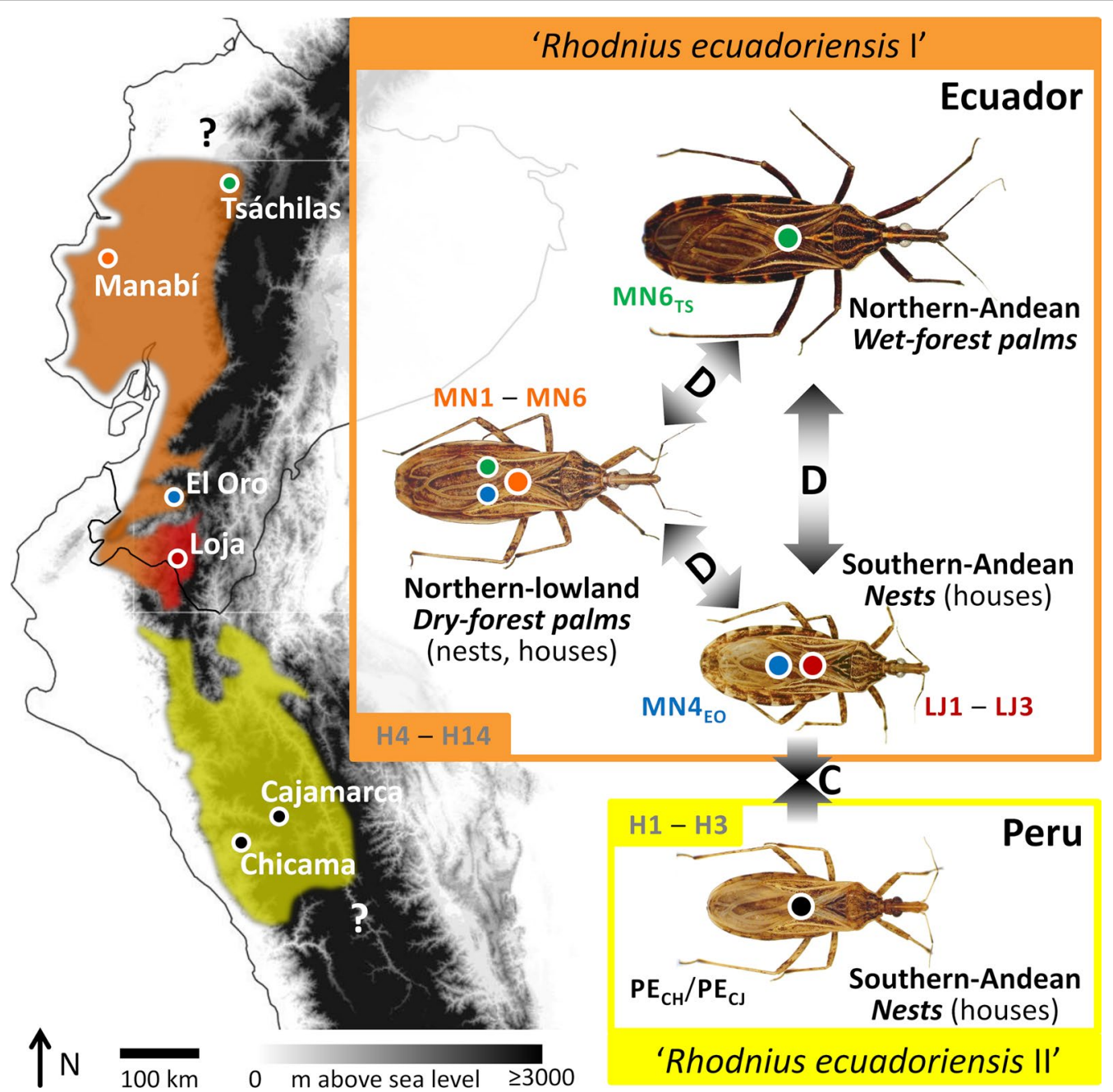

Fig. 10 Divergence and convergence in Triatominae: genotypes, phenotypes and habitats of Rhodnius ecuadoriensis populations. The map illustrates the approximate distribution of the two major R. ecuadoriensis lineages: the Ecuadorian lineage (orange; "Rhodnius ecuadoriensis I" of $[8,18])$ and the Peruvian lineage (yellow; "Rhodnius ecuadoriensis II" of $[8,18]$ ). Question marks highlight uncertainties as to the species' northern and southern range limits. The reddish shade in Loja suggests possible, partial differentiation of local populations in the Catamayo-Chira basin, as indicated by the identification of three closely related cytb haplotypes (LJ1-LJ3) not shared with other populations (Figs. 7, 8) and by limited microsatellite [41] and 2b-RAD (restriction site-associated DNA tag sequencing/genotyping based on type IIB restriction enzymes) genotyping data [79]. Colored circles show the approximate geographic location (on the map) of cytb haplotypes and their correspondence with each phenotype (on bug pictures); color codes are as in Figs. 1 and 5-8. Nuclear ITS2 haplotypes differ between Ecuadorian (H2-H14; orange box) and Peruvian bugs ( $\mathrm{H} 1-\mathrm{H} 3$; yellow box), with no clear geographic, ecological or phenotype-related genetic structuring within Ecuador. The primary (natural) habitat of each population is given in bold italics. Gray-white arrows emphasize phenotypic divergence $(D)$ or convergence $(C)$ between populations

sequences and forewing (plus, to a lesser extent, head) shapes strongly suggest incipient evolutionary divergence (Fig. 10; Table 3; Additional file 4: Figure S1). Below we argue that local adaptation to distinct microhabitats is probably the key driver underpinning this remarkable example of phenotypic diversity within a single putative species.

Triatomines are blood-sucking bugs that live in sheltered microhabitats with a more-or-less stable food supply [1, 2, 27]. All Rhodnius species, for example, are primarily arboreal; most are tightly associated with palmcrown habitats, but some species and populations also exploit vertebrate nests built on tree branches, inside tree hollows, in bromeliads or on palm crowns [2, 27, 29]. Populations of a few Rhodnius species also occupy human-made habitats and can transmit T. cruzi to people and their domestic mammals [1, 3, 27]. Rhodnius ecuadoriensis is one such species. In the wild, it seems to be primarily associated with the endemic Phytelephas aequatorialis palm of western Ecuador, but has also 
been found in vertebrate nests; southern-Andean populations, in particular, occur in dry ecoregions in which palms are rare or absent, and appear to have shifted to squirrel, bird and opossum nests [1, 2, 26-34]. In addition, some $R$. ecuadoriensis populations can infest houses and peridomestic structures-with a preference for hen nests, guinea-pig pens and dovecotes $[1,24-27,35,36$, $38,39]$. These synanthropic populations are major local vectors of human Chagas disease [1, 24-27, 36-39]; importantly, available phenotypic, genetic and behavioral evidence suggests that they most likely represent subsets of locally sympatric wild populations [36, 40-43]. At a broader spatial scale, $R$. ecuadoriensis is the only named Rhodnius species known to occur on the western side of the Andes south of the Magdalena-Urabá moist forests of northwestern Colombia; the Chocó rainforests along the Colombian Pacific coast separate $R$. ecuadoriensis from its sister-species clade, $R$. pallescens- $R$. colombiensis $[8,18]$. Within its range, $R$. ecuadoriensis occurs in widely different ecoregions $[8,18,25,26]$. In centralwestern Ecuador, presence records range from Andean wet premontane (or "cloud") forests to semiarid parts of the coastal lowlands [25]. In southwestern Ecuador and northwestern Peru, the species occupies seasonally dry inter-Andean valleys up to $2700 \mathrm{~m}$ a.s.l. and is often found infesting houses [25, 26].

We reasoned that the broad ecological flexibility of $R$. ecuadoriensis was likely to correlate with similarly broad intraspecific variation, and set out to examine the signs of diversification and adaptation in this locally important vector species. To address both macro-scale diversity and micro-scale adaptations, we analyzed mitochondrial and nuclear DNA markers that have proven useful in similar study systems $[5-9,11,12,15-17,19,72-74,80-84]$ and undertook a detailed qualitative/quantitative phenotypic assessment including head and forewing morphometrics $[22,40,49,51-53]$; we then used rich, specimen-specific ecological metadata (Additional file 1: Table S1) to guide the interpretation of results.

\section{Macro-scale diversity: lineages and shape patterns}

Our results provide strong support to the view that $R$. ecuadoriensis is composed of two major, independently evolving lineages $[8,18]$ (Table 3). The core Ecuadorian lineage has been dubbed "R. ecuadoriensis group I" [18]; it occupies highly diverse ecoregions from the wet central-western Ecuadorian Andes down to the drier valleys of the Catamayo-Chira basin-apparently always north of the Sechura desert-Huamaní range (Figs. 1, 10). The Peruvian lineage, or " $R$. ecuadoriensis group II" [18], occurs in the dry inter-Andean valleys of northwestern Peru, from the Huancabamba depression down to (and apparently excluding) the semiarid Santa river basin $[8$,
25, 26]; this distribution includes: (i) Pacific-slope valleys, from the eastern edge of the Sechura desert to the Chicama and perhaps Moche basins; and (ii) the Amazonslope upper Marañón valley (Table 1; Figs. 1, 10). Cytb divergence levels suggest $[17,83]$ that these two lineages may have been evolving independently for 2.2-3.6 million years, with a late Pliocene-early Pleistocene most recent common ancestor. K2p distances (4.0-4.9\%) are larger than those separating $R$. prolixus from its sister species, the partly sympatric $R$. robustus I (3.0-3.3\%) $[8$, 17].

Although these differences are in the limit of what Wiemers and Fiedler [85] consider "low" levels of mitochondrial DNA K2p sequence divergence between reciprocally monophyletic sister clades, our ITS2 (Fig. 7) and multispecies coalescent results (Table 3; Fig. 9) lend further support to the hypothesis that Ecuadorian and Peruvian $R$. ecuadoriensis are independently evolving lineages $[8,18,67]$. An allozyme electrophoresis study [86] including $R$. ecuadoriensis colony bugs originally from Ecuador (Manabí and El Oro) and Peru (Cajamarca; same colony as $\left.\mathrm{PE}_{\mathrm{CJ}}\right)$ provides additional insight into divergence at multiple nuclear loci; in particular, different alleles of $M d h$, Pep3 and Pep4, for which no heterozygotes were detected, segregated "according to the geographical origin of the specimens from Ecuador and Peru" ([86], p. $303)$. A later study showed that the $45 \mathrm{~S}$ rDNA gene cluster occupies different chromosomal loci in Ecuadorian (X and Y chromosomes; bugs from Manabí) and Peruvian specimens (X chromosomes only; bugs from La Libertad) [87]. Taken together, our DNA results and these independent findings are strongly suggestive of a relatively long history of independent evolution of Ecuadorian and Peruvian $R$. ecuadoriensis lineages, likely involving ongoing or very recent speciation. Our detailed appraisal of phenotypes (Table 1; Figs. 3, 4; see also Additional file 3: Text S1) provides the basis for distinguishing bugs carrying Peruvian and Ecuadorian genotypes; we expect professional taxonomists to examine our findings and, if warranted, formally describe a new Rhodnius species based on Peruvian material.

Our DNA-based results, in addition, broadly mirrored those of forewing and (size-free) head shape analyses; as previously suggested [51, 53], explicit size partitioning was necessary to single out genetically distinct groups after traditional morphometrics. We expected wing shape to be relatively conserved because of the crucial role of flight in adult-bug dispersal $[1,27]$ and the importance of wing geometry for flight efficiency [88]. Forewing shape differences reflected the relatively deep genetic divergence of the Ecuadorian and Peruvian lineages (Figs. 6b, $7,8)$. On the other hand, the adaptive value of head-shape 
variants within triatomine-bug species remains obscure. Our results suggest that, when size effects are removed, $R$. ecuadoriensis head shape may fairly mirror genetic divergence (Figs. 5e, 7, 8). In general, the elongated heads of northern, primarily palm-dwelling populations (Tsáchilas and Manabí) sharply contrast with the shorter, stouter heads of southern-Andean populations (Figs. 3, 5c, 6a). As discussed below, this may be related to a transition from palm to nest microhabitats $[2,89]$.

\section{Phenotypic variability at the micro-scale: microhabitat adaptations}

Elongated heads and medium-sized bodies (relative to other triatomines) are characteristic of the genus Rhodnius, which mainly comprises palm-living species $[1$, 2 , 29]. The few exceptions to this morphological "rule" seem to correspond to nest-dwelling species [2]. The Psammolestes, for example, are an atypical Rhodnius sub-lineage $[5,6,8-10,13]$ with strikingly distinct phenotypes-very small bodies and very short-and-stout heads $[1,2]$. These clearly derived traits are probably related to the adaptation of the Psammolestes common ancestor to the enclosed vegetative nests of some ovenbirds [2, 18, 22]. Among Rhodnius species, the most similar in head shape and body size to the typical, southern forms of R. ecuadoriensis is R. paraensis, which has to date only been reported from the tree-hole nests of arboreal Echimys spiny rats [1, 2, 27, 90]. Rhodnius domesticus also has a relatively short and stout head for the genus; it is too among the few Rhodnius species not specializing in palm habitats-instead, it is associated with the nests and shelters of Phillomys tree-rats and Didelphis and Marmosa opossums in bromeliads and hollow tree-trunks $[1,2,27]$.

These observations suggest that the reduced body size and head dimensions of typical $R$. ecuadoriensis populations may be a consequence of their shifting from the original palm-crown habitat to new, vertebrate-nest microhabitats [2]. This shift likely occurred in the dry Andean environments of southwestern Ecuador and northwestern Peru that overall lack native palm populations [25, 26, 30, 32, 39]. In Loja, wild $R$. ecuadoriensis often breed inside the nests of the tree-squirrel, Sciurus stramineus/nebouxii [2, 30, 32, 33, 91]. Within nest microhabitats, the close physical proximity between the (virtually ectoparasitic) bugs and their hosts would relax selection for long/narrow heads and mouthparts, which may be required for biting free-ranging hosts more safely (at a longer distance) and sucking their blood faster (thanks to larger cibarial-pump muscles) [89, 92]. In addition, and as has been also postulated for domestic triatomine populations [4], an overall more predictable food supply within a nest (or human dwelling), with a higher likelihood of repeated smaller blood meals, would relax the need for growing bigger bodies capable of storing larger amounts of blood [89]. Finally, hostmediated (passive) dispersal is probably more important among nest-dwelling than among palm-dwelling bugs, which might reduce the need for highly efficient flight, hence relaxing selection for elongated wings [27, 88]. We note that in Manabí $R$. ecuadoriensis occurs both in $P h$. aequatorialis palms and in bird and mammal nests built on palms, trees or bromeliads [2, 28, 29, 31, 93]. This might help explain the intermediate phenotypes, including body size and head/forewing shape, of these primarily palm-dwelling lowland populations (Figs. 3, 5, 6; Additional file 4: Figure S1).

We also found a striking variability of overall color among $R$. ecuadoriensis populations. In particular, the dark hue of Tsáchilas bugs differs markedly from the typical brown-yellowish, straw-like color of the remaining populations (Fig. 3). This straw-like coloration is shared by $R$. pallescens and $R$. colombiensis $[1,77]$, suggesting that it is plesiomorphic (Additional file 4: Figure S1). In the fresh, field-caught bugs we studied, color variation involved mainly pigmentation intensity rather than discrete changes in the arrangement of markings. For example, some typically colored bugs may have a larger amount of irregular dark spots and markings, or their dark markings may have larger surfaces. The highly divergent Tsáchilas forms have large and abundant black markings on a reddish-brown, generally very dark background color. Although Tsáchilas and Manabí populations share $\mathrm{Ph}$. aequatorialis as their primary ecotope, extensive field observations [28, 76] led us to notice that palm-crown microhabitats are often quite different in the wet Andes and the dry lowlands. In the dry Manabí lowlands, dead palm fronds and fibers tend to dry up, resulting in a straw-colored habitat substrate. In contrast, dead palm fronds and fibers quickly decay in the wet Andes foothills-where, in addition, large amounts of epiphytes grow on the palms. As a result, the palm-crown microhabitat of northern-Andean Tsáchilas bugs has a dark, actually reddish-brown, background color. Hence, the color of palm-dwelling bugs from each area (Fig. 3) closely matches their palm-microhabitat background, suggesting camouflage against the substrate $[90,94-96]$. Also in line with this "camouflage hypothesis", southern $R$. ecuadoriensis populations (Fig. 3) associate with rodent and/or bird nests made of light brown-yellowish materials-twigs, dry grass/leaves and straw. We therefore suggest that sight-guided predators likely provide the main selective pressure underlying color variability in $R$. ecuadoriensis-and probably in other triatomines. 


\section{Caveats}

The first, general caveat of this study is that the results are based on a relatively limited (albeit overall wellrepresentative) sample of geographic-ecological populations and on only two genetic loci (albeit two that are informative for problems like the one we tackled). Our interpretations of these results, therefore, are best viewed as testable hypotheses to be addressed by future research. This should ideally include: (i) the study of natural populations along putative contact zones between genetic and phenotypic variants (e.g. on the Huamaní range or along the Andes foothills from Tsáchilas down to El Oro; Fig. 1), as well as in the Chocó wet forests of Ecuador and Colombia; (ii) population genetics/genomics analyses [41, 43, 79]; (iii) assessing the extent of range overlap and cross-fertility between lineages and populations [97]; or (iv) a detailed characterization of microhabitats, with an emphasis on bug/background color matching [98]. Second, the microhabitat associations we consider (Table 1) refer to the known primary habitats of natural wild populations [1, 2, 24-39]; we note, however, that the evidence of a primary link with vertebrate nests is still weak for wild Peruvian populations [2, 26, 27, 34]. Further, our southern-Andean samples came from human-made, not wild, microhabitats; as has been shown for southern-Andean Ecuadorian populations, we assume that the phenotypes [40] and genotypes [41] of these bugs do not differ significantly (or indeed at all) from those of their wild, nest-dwelling conspecifics (see also [36, 42]). This is also consistent with the patterns of genetic and/or morphometric similarity of wild and non-wild bugs described for northern-lowland $R$. ecuadoriensis $[40,43]$ and for other triatomine-bug species that often infest houses within their native ranges-including, for example, $R$. prolixus [82], T. infestans [52, 99], T. brasiliensis $[100,101]$ or $T$. dimidiata [102]. Finally, a small minority of the specimens we studied did not come from field collections. Seven bugs were from laboratory colonies (Additional file 1: Table S1), but, except for one head-size outlier (Fig. 5), we found no differences between these bugs and their field-caught relatives. Our sample also included two bugs from older collections (Additional file 1: Table S1); because the color of pinned bugs can change over time, we did not consider these two specimens in our qualitative assessment of phenotypes-for which we only used bugs that were fresh at the time of appraisal.

\section{Conclusions}

Adaptation of an organism to its habitat becomes particularly evident when a human observer can predict habitat traits from organism traits. Our findings suggest that this is likely the case with $R$. ecuadoriensis populations. Thus, bug color predicts microhabitat background color, suggesting an adaptive response to selective pressure from sight-guided predators [90, 96]. The small body size and short/stout heads of southernAndean bugs predict $[2,89]$ that wild populations preferentially exploit nest microhabitats-a proposition for which there is some empirical evidence, including abundant squirrel-nest populations [2, 30, 32, 33] and a strong association of domestic bugs with hen nests and guinea-pig pens [1, 26, 27, 35, 36, 39]. Importantly, we have also shown that populations with extremely divergent phenotypes can share their genetic backgrounds, at least for the two loci we examined; also importantly, our sequence data indicate that genetic similarity among Ecuadorian bugs is not due to mitochondrial DNA introgression [78]. In addition, our data reveal that southern-Andean $R$. ecuadoriensis populations with near-sibling naked-eye phenotypes belong in two distinct evolutionary lineages-the Ecuadorian "R. ecuadoriensis I" and the Peruvian "R. ecuadoriensis II" [18]. This can have implications for taxonomy and, hence, for the interpretation of taxonomy-dependent research results. We note, for example, that the reference $R$. ecuadoriensis strain kept at the LNIRTT (Fiocruz, Brazil) has the PE cytb haplotype, which is nearly $5 \%$ divergent from the LJ haplotypes that geographically correspond to the species' type material from Catamayo, Loja [45]. In their classic revision, Lent and Wygodzinsky [1] illustrate R. ecuadoriensis with a Peruvian bug from Cajamarca (Fig. 257 in [1]). Peruvian- and Ecuadorian-lineage bugs are also clearly divergent in forewing and (size-free) head shape, at several allozyme loci [86] and cytogenetically [87].

In sum, our detailed appraisal of phenotypic and genetic diversity in $R$. ecuadoriensis revealed phenotypic divergence within genetically homogeneous populations and phenotypic convergence of genetically distinct lineages likely on their way to speciation-if not separate species already. Such remarkable, bidirectional phenotypic change within a single nominal taxon was apparently associated with adaptation to particular microhabitats. These findings shed new light on the origins of phenotypic diversity in the Triatominae, warn against excess reliance on phenotype-based triatominebug systematics, and confirm the Triatominae as an informative model-system for the study of phenotypic change under ecological pressure.

\section{Abbreviations}

BF: Bayes factor; BIC: Bayesian information criterion; BPP: Bayesian posterior probability; CV: Canonical variate; CVA: Canonical variate analysis; cytb: Mitochondrial cytochrome $b$ gene; EO: El Oro province, Ecuador; ESS: Effective 
sample size; ITS2: Nuclear ribosomal second internal transcribed spacer; K2p: Kimura two-parameter genetic distance; L: Loja province, Ecuador; LNIRTT : Laboratório Nacional e Internacional de Referência em Taxonomia de Triatomíneos, Fiocruz, Brazil; MCMC: Markov chain Monte Carlo; mL: Marginal likelihood; MN: Manabí province, Ecuador; PC: Principal component; PCA: Principal component analysis; PE: Peru; SE: Standard error; TPS: Thin plate spline; TS: Santo Domingo de los Tsáchilas province, Ecuador; 2b-RAD: Restriction site-associated DNA tag sequencing/genotyping based on type IIB restriction enzymes.

\section{Supplementary Information}

The online version contains supplementary material available at https://doi. org/10.1186/s13071-021-04647-z.

Additional file 1: Table S1. Populations, specimen details and haplotype codes of 106 Rhodnius ecuadoriensis bugs used in morphometric and/or molecular analyses. A summary table with the numbers of bugs used in each analysis is also provided.

Additional file 2: Alignment S1. Mitochondrial cytochrome $b$ haplotypes in Rhodnius ecuadoriensis from Ecuador and Peru, plus outgroup species (R. colombiensis, R. pallescens, R. pictipes).

Additional file 3: Text S1. Detailed descriptions of the diverse Rhodnius ecuadoriensis phenotypes.

Additional file 4: Figure S1. Phenotype-microhabitat-phylogeny correspondences. Multispecies coalescent species tree (as in Fig. 9 of the main text), with pictures (approximately to the same scale) of adult Rhodnius ecuadoriensis and its closest relatives-R. colombiensis, R. pallescens and $R$. pictipes. The distribution of phenotypes along the phylogeny suggests that the common ancestor of the diverse R. ecuadoriensis forms was most likely a relatively large, straw-like-colored bug. Similarly, the distribution of primary microhabitats suggests that a shift of southern-Andean populations from palm crowns (green stars) to vertebrate nests (orange circles) resulted in convergence towards the small-size, short-head/wing typical R. ecuadoriensis phenotype; the combined star/circle symbol indicates that northern-lowland Manabí bugs are primarily palm-dwelling but may also exploit nest microhabitats. Rhodnius ecuadoriensis populations: N-A Northern-Andean (Tsáchilas), N-L northern-lowland (Manabí), S-A southern-Andean (El Oro and Loja in Ecuador; La Libertad and Cajamarca in Peru).

Additional file 5: Figure S2. Centroid-size comparisons. Population boxplots and Tukey-Kramer (T-K) tests for head and forewing centroid sizes derived from geometric morphometrics.

Additional file 6: Alignment S2. Fourteen nuclear ITS2 haplotypes found in Rhodnius ecuadoriensis from Ecuador and Peru.

Additional file 7: Alignment S3. Nuclear ITS2 haplotypes in Rhodnius ecuadoriensis from Ecuador and Peru, plus outgroup species (R. colombiensis, R. pallescens and R. pictipes).

\section{Acknowledgements}

We thank CAC Cuba and J Jurberg for providing bugs, and the staff of the Ecuadorian Malaria Control Service for field assistance. The findings and conclusions in this report are those of the authors and do not necessarily represent the official position of the US Centers for Disease Control and Prevention/ the Agency for Toxic Substances and Disease Registry.

\section{Authors' contributions}

FA-F, FAM, JSP and MAM conceived the study. FA-F, MDB, MA and MAM raised funds. FA-F, MA and MAM administered different parts of the project. FA-F, FAM, MGP, JSP, MDB, MAZ, MA, CBB, SM-C and MAM contributed to the development of research methods. FA-F, FAM, MGP, JSP, MDB, MAZ and MA performed research. FA-F, FAM, MGP, JSP, MDB and MAZ curated different datasets and analyzed the data. MAM, MDB, SM-C and CBB supervised research. FA-F and MAM drafted the first version of the manuscript; all authors contributed to the interpretation of results and commented on manuscript drafts. All authors read and approved the final manuscript.

\section{Funding}

UNICEF/UNDP/World Bank/WHO TDR (Grant 970195); Red de Investigación de Centros de Enfermedades Tropicales_-RICET, Ministerio de Salud y Consumo, Madrid, Spain (Grant No. RD16/0027/0023 of the PN de I+D+I, ISCIII-Subdirección General de Redes y Centros de Investigación Cooperativa RETICS); and PROMETEO Program, Ayudas para Grupos de Investigación de Excelencia, Generalitat Valenciana, Valencia, Spain (Grant No. 2016/099).

\section{Availability of data and materials}

Data supporting the conclusions of this article are included in the article and its additional files. DNA sequences have been deposited in GenBank under accession numbers MT497021-MT497038 for mitochondrial cytb haplotypes and KT267937-KT267950 plus KT351069-KT351071 for nuclear rDNA ITS2 haplotypes.

\section{Declarations}

Ethics approval and consent to participate

Our study did not involve endangered or protected species; collection of disease vectors did not require specific permits at the time this project was carried out. Prior to field activities, we obtained oral informed consent from all home- and landowners.

\section{Consent for publication}

Not applicable.

\section{Competing interests}

The authors declare that they have no competing interests.

\section{Author details}

${ }^{1}$ Núcleo de Medicina Tropical, Faculdade de Medicina, Universidade de Brasília, Brasília, Brazil. ${ }^{2}$ Faculty of Infectious and Tropical Diseases, London School of Hygiene and Tropical Medicine, London, UK. ${ }^{3}$ Laboratório de Epidemiologia e Sistemática Molecular, Instituto Oswaldo Cruz-Fiocruz, Rio de Janeiro, Brazil. ${ }^{4}$ Division of Vector-Borne Diseases, Centers for Disease Control and Prevention, Fort Collins, USA. ${ }^{5}$ Laboratório de Mosquitos Transmissores de Hematozoários, Instituto Oswaldo Cruz-Fiocruz, Rio de Janeiro, Brazil. ${ }^{6}$ Departamento de Parasitología, Facultad de Farmacia, Universidad de Valencia, Valencia, Spain. ${ }^{7}$ Facultad de Ciencias Médicas, Universidad Central del Ecuador, Quito, Ecuador. ${ }^{8}$ Instituto Juan César García, Quito, Ecuador.

Received: 15 November 2020 Accepted: 16 February 2021

Published online: 08 April 2021

\section{References}

1. Lent H, Wygodzinsky P. Revision of the Triatominae (Hemiptera, Reduviidae), and their significance as vectors of Chagas' disease. Bull Am Mus Nat Hist. 1979;163:123-520.

2. Abad-Franch F, Gurgel-Gonçalves R. The ecology and natural history of wild Triatominae in the Americas. In: Guarneri AA, Lorenzo MG, editors. Triatominae: the biology of Chagas disease vectors Entomology in focus, vol. 5. Cham: Springer; 2021. (In press).

3. World Health Organization. Control of Chagas disease: second report of the WHO Expert Committee. WHO Tech Rep Ser. 2002;905:i-vi, 1-109.

4. Dujardin JP, Panzera F, Schofield CJ. Triatominae as a model of morphological plasticity under ecological pressure. Mem Inst Oswaldo Cruz. 1999;94(Suppl 1):223-8.

5. Monteiro FA, Escalante AA, Beard CB. Molecular tools and triatomine systematics: a public health perspective. Trends Parasitol. 2001;17:344-7.

6. Abad-Franch F, Monteiro FA. Molecular research and the control of Chagas disease vectors. An Acad Bras Ciencias. 2005;77:437-54.

7. Mas-Coma S, Bargues MD. Populations, hybrids and the systematic concepts of species and subspecies in Chagas disease triatomine vectors inferred from nuclear ribosomal and mitochondrial DNA. Acta Trop. 2009;110:112-36. 
8. Monteiro FA, Weirauch C, Felix M, Lazoski C, Abad-Franch F. Evolution, systematics, and biogeography of the Triatominae, vectors of Chagas disease. Adv Parasitol. 2018;99:265-344.

9. Monteiro F, Wesson DM, Dotson EM, Schofield CJ, Beard CB. Phylogeny and molecular taxonomy of the Rhodniini derived from mitochondrial and nuclear DNA sequences. Am J Trop Med Hyg. 2000;62:460-5.

10. Monteiro FA, Lazoski C, Noireau F, Sole-Cava AM. Allozyme relationships among ten species of Rhodniini, showing paraphyly of Rhodnius including Psammolestes. Med Vet Entomol. 2002;16:83-90.

11. Marcilla A, Bargues MD, Ramsey JM, Magallon-Gastelum E, SalazarSchettino PM, Abad-Franch F, et al. The ITS-2 of the nuclear rDNA as a molecular marker for populations, species, and phylogenetic relationships in Triatominae (Hemiptera: Reduviidae), vectors of Chagas disease. Mol Phylogenet Evol. 2001;18:136-42.

12. Marcilla A, Bargues MD, Abad-Franch F, Panzera F, Carcavallo RU, Noireau F, et al. Nuclear rDNA ITS-2 sequences reveal polyphyly of Panstrongylus species (Hemiptera: Reduviidae: Triatominae), vectors of Trypanosoma cruzi. Infect Genet Evol. 2002;21:225-35.

13. Hypsa V, Tietz DF, Zrzavy J, Rego ROM, Galvão C, Jurberg J. Phylogeny and biogeography of Triatominae (Hemiptera: Reduviidae): molecular evidence of a New World origin of the Asiatic clade. Mol Phylogenet Evol. 2002;23:447-57.

14. Patterson JS, Gaunt MW. Phylogenetic multi-locus codon models and molecular clocks reveal the monophyly of haematophagous reduviid bugs and their evolution at the formation of South America. Mol Phylogenet Evol. 2010;56:608-21.

15. Monteiro F, Perez R, Panzera F, Dujardin JP, Galvão C, Rocha D, et al. Mitochondrial DNA variation of Triatoma infestans populations and its implication on the specific status of T. melanosoma. Mem Inst Oswaldo Cruz. 1999;94(Suppl. 1):229-38.

16. Bargues MD, Klisiowicz DR, Panzera F, Noireau F, Marcilla A, Perez R, et al. Origin and phylogeography of the Chagas disease main vector Triatoma infestans based on nuclear rDNA sequences and genome size. Infect Genet Evol. 2006;6:46-62.

17. Monteiro FA, Barrett TV, Fitzpatrick S, Cordon-Rosales C, Feliciangeli D, Beard CB. Molecular phylogeography of the Amazonian Chagas disease vectors Rhodnius prolixus and R. robustus. Mol Ecol. 2003;12:997-1006.

18. Abad-Franch F, Monteiro FA, Jaramillo ON, Gurgel-Gonçalves R, Dias FBS, Diotaiuti L. Ecology, evolution, and the long-term surveillance of vector-borne Chagas disease: a multi-scale appraisal of the tribe Rhodniini (Triatominae). Acta Trop. 2009;110:159-77.

19. Brito RN, Geraldo JA, Monteiro FA, Lazoski C, Souza RCM, Abad-Franch F. Transcriptome-based molecular systematics: Rhodnius montenegrensis (Triatominae) and its position within the Rhodnius prolixus-Rhodnius robustus cryptic-species complex. Parasit Vectors. 2019;12:305.

20. da Rosa JA, Rocha CS, Gardim S, Pinto MC, Mendonça VJ, Ferreira Filho $J C R$, et al. Description of Rhodnius montenegrensis sp. nov. (Hemiptera: Reduviidae: Triatominae) from the state of Rondônia, Brazil. Zootaxa. 2012;3478:62-76.

21. Souza ED, Von Atzingen NC, Furtado MB, de Oliveira J, Nascimento $J \mathrm{D}$, Vendrami DP, et al. Description of Rhodnius marabaensis sp. n. (Hemiptera, Reduviidae, Triatominae) from Pará State, Brazil. Zookeys. 2016;621:45-62.

22. Dujardin J-P, Costa J, Bustamante D, Jaramillo N, Catala S. Deciphering morphology in Triatominae: the evolutionary signals. Acta Trop. 2009:110:101-11.

23. Noireau F, Gutierrez T, Zegarra M, Flores R, Breniere F, Cardozo L, et al Cryptic speciation in Triatoma sordida (Hemiptera:Reduviidae) from the Bolivian Chaco. Trop Med Int Health. 1998;3:364-72.

24. Aguilar VHM, Abad-Franch F, Racines VJ, Paucar CA. Epidemiology of Chagas disease in Ecuador. A brief review. Mem Inst Oswaldo Cruz. 1999;94(Suppl. 1):387-93.

25. Abad-Franch F, Paucar CA, Carpio CC, Cuba Cuba CA, Aguilar VHM, Miles MA. Biogeography of Triatominae (Hemiptera: Reduviidae) in Ecuador: implications for the design of control strategies. Mem Inst Oswaldo Cruz. 2001:96:611-20.

26. Cuba Cuba CA, Abad-Franch F, Roldan RJ, Vargas VF, Pollack VL, Miles $M A$. The triatomines of northern Peru, with emphasis on the ecology and infection by trypanosomes of Rhodnius ecuadoriensis (Triatominae). Mem Inst Oswaldo Cruz. 2002;97:175-83.
27. Barrett TV. Advances in triatomine bug ecology in relation to Chagas' disease. In: Harris $\mathrm{KH}$, organizer. Advances in disease vector research, vol. 8. New York: Springer-Verlag; 1991. pp. 143-76.

28. Abad-Franch F, Palomeque FS, Aguilar HM, Miles MA. Field ecology of sylvatic Rhodnius populations (Heteroptera, Triatominae): risk factors for palm tree infestation in western Ecuador. Trop Med Int Health. 2005:10:1258-66.

29. Abad-Franch F, Lima MM, Sarquis O, Gurgel-Gonçalves R, SanchezMartin M, Calzada J, et al. On palms, bugs, and Chagas disease in the Americas. Acta Trop. 2015;151:126-41.

30. Grijalva MJ, Villacis AG. Presence of Rhodnius ecuadoriensis in sylvatic habitats in the southern highlands (Loja Province) of Ecuador. J Med Entomol. 2009:46:708-11.

31. Suarez-Davalos V, Dangles O, Villacis AG, Grijalva MJ. Microdistribution of sylvatic triatomine populations in central-coastal Ecuador. J Med Entomol. 2010;47:80-8.

32. Grijalva MJ, Suarez-Davalos V, Villacis AG, Ocaña-Mayorga S, Dangles $O$. Ecological factors related to the widespread distribution of sylvatic Rhodnius ecuadoriensis populations in southern Ecuador. Parasit Vectors. 2012;5:17.

33. Ocaña-Mayorga S, Lobos SE, Crespo-Pérez V, Villacis AG, Pinto CM, Grijalva MJ. Influence of ecological factors on the presence of a triatomine species associated with the arboreal habitat of a host of Trypanosoma cruzi. Parasit Vectors. 2018;1 1:567.

34. Herrer A, Wygodzinsky P, Napan M. Presencia de Trypanosoma rangeli Tejera, 1920, en el Perú. 1. El insecto vector, Rhodnius ecuadoriensis Lent \& León, 1958. Rev Biol Trop. 1972;20:141-9.

35. Abad-Franch F, Aguilar VHM, Paucar CA, Lorosa ES, Noireau F. Observations on the domestic ecology of Rhodnius ecuadoriensis (Triatominae). Mem Inst Oswaldo Cruz. 2002;97:199-202.

36. Grijalva MJ, Villacis AG, Ocaña-Mayorga S, Yumiseva CA, Moncayo AL, Baus EG. Comprehensive survey of domiciliary triatomine species capable of transmitting Chagas disease in southern Ecuador. PLoS Negl Trop Dis. 2015;9:e0004142.

37. Black CL, Ocaña-Mayorga S, Riner DK, Costales JA, Lascano MS, ArcosTeran $L$, et al. Seroprevalence of Trypanosoma cruzi in rural Ecuador and clustering of seropositivity within households. Am J Trop Med Hyg. 2009:81:1035-40

38. Grijalva MJ, Villacis AG, Moncayo AL, Ocaña-Mayorga S, Yumiseva CA, Baus EG. Distribution of triatomine species in domestic and peridomestic environments in central coastal Ecuador. PLoS Negl Trop Dis. 2017:11:e0005970.

39. Cuba CAC, Vargas F, Roldan J, Ampuero C. Domestic Rhodnius ecuadoriensis (Hemiptera, Reduviidae) infestation in Northern Peru: a comparative trial of detection methods during a six-month follow-up. Rev Inst Med Trop Sao Paulo. 2003;45:85-90.

40. Villacis AG, Grijalva MJ, Catala SS. Phenotypic variability of Rhodnius ecuadoriensis populations at the Ecuadorian central and southern Andean region. J Med Entomol. 2010;47:1034-43.

41. Villacis AG, Marcet PL, Yumiseva CA, Dotson EM, Tibayrenc M, Breniere $\mathrm{SF}$, et al. Pioneer study of population genetics of Rhodnius ecuadoriensis (Hemiptera: Reduviidae) from the central coast and southern Andean regions of Ecuador. Infect Genet Evol. 2017:53:116-27.

42. Grijalva MJ, Villacis AG, Ocaña-Mayorga S, Yumiseva CA, Baus EG. Limitations of selective deltamethrin application for triatomine control in central coastal Ecuador. Parasit Vectors. 2011:4:20.

43. Muñoz-Tobar SI, Abad-Franch F, Grijalva MJ. Rhodnius pallescens microsatellite markers for population genetic analysis in Rhodnus ecuadoriensis: preliminary assessment. Rev Ecuat Med Cienc Biol. 2019;40:87-93.

44. Gonçalves TCM, Almeida MD, Jurberg J, Lent H. Lista dos exemplarestipo de triatomíneos depositados na Coleção Entomológica do Instituto Oswaldo Cruz, Rio de Janeiro (Hemiptera: Rediviidae). Mem Inst Oswaldo Cruz. 1993;88:327-33.

45. Lent H, Leon LA. Um novo Rhodnius Stål do Ecuador (Hemiptera, Reduviidae). Rev Bras Biol. 1958;18:181-5.

46. Bates D, Mächler M, Bolker B, Walker S. Fitting linear mixed-effects models using Ime4. J Stat Softw. 2014;67:1-48.

47. R Development Core Team. R: a language and environment for statistical computing. Version 3.6.3. Vienna: R Foundation for Statistical Computing. 2020. https://www.R-project.org. 
48. Darroch JN, Mosiman JE. Canonical and principal components of shape. Biometrika. 1985;72:241-52.

49. Patterson JS, Schofield CJ, Dujardin J-P, Miles MA. Population morphometric analysis of the tropicopolitan bug Triatoma rubrofasciata and relationships with Old World species of Triatoma: evidence of New World ancestry. Med Vet Entomol. 2001;15:443-51.

50. Wilks SS. Certain generalizations in the analysis of variance. Biometrika. 1932;24:471-94.

51. Vitt LJ, Caldwell JP, Zani PA, Titus TA. The role of habitat shift in the evolution of lizard morphology: evidence from tropical Tropidurus. Proc Natl Acad Sci USA. 1997;94:3828-32.

52. Dujardin J-P, Bermudez H, Casini C, Schofield CJ, Tibayrenc M. Metric differences between silvatic and domestic Triatoma infestans (Heteroptera: Reduviidae) in Bolivia. J Med Entomol. 1997:34:544-51.

53. Dujardin J-P, Chavez T, Moreno JM, Machane M, Noireau F, Schofield CJ. Comparison of isoenzyme electrophoresis and morphometric analysis for phylogenetic reconstruction of the Rhodniini (Hemiptera: Reduviidae:Triatominae). J Med Entomol. 1999;36:653-9.

54. Rohlf FJ. NTSYS. Numerical taxonomy and multivariate analysis system. Version 2.10y. New York: Exeter Software; 2001.

55. Rohlf FJ. tpsDig v. 1.18. Stony Brook: Department of Ecology and Evolution, State University of New York. 1999. http://life.bio.sunysb.edu/ morph/

56. Bookstein FL. Morphometric tools for landmark data: geometry and biology. New York: Cambridge University Press; 1991.

57. Rohlf FJ. tpsRelw, v. 1.18. Stony Brook: Department of Ecology and Evolution, State University of New York; 1999. http://life.bio.sunysb.edu/ morph/

58. Bargues MD, Zuriaga MA, Mas-Coma S. Nuclear rDNA pseudogenes in Chagas disease vectors: evolutionary implications of a new 5.8S+ITS-2 paralogous sequence marker in triatomines of North, Central and northern South America. Infect Genet Evol. 2014;21:134-56.

59. Zuriaga MA, Mas-Coma S, Bargues MD. A nuclear ribosomal DNA pseudogene in triatomines opens a new research field of fundamental and applied implications in Chagas disease. Mem Inst Oswaldo Cruz. 2015;110:353-62.

60. Katoh K, Standley DM. MAFFT multiple sequence alignment software version 7: improvements in performance and usability. Mol Biol Evol. 2013;30:772-80.

61. Kumar S, Stecher G, Li M, Knyaz C, Tamura K. MEGA X: molecular evolutionary genetics analysis across computing platforms. Mol Biol Evol. 2018;35:1547-9.

62. Bouckaert R, Drummond AJ. bModelTest: Bayesian phylogenetic site model averaging and model comparison. BMC Evol Biol. 2017;17:42.

63. Heled J, Drummond AJ. Bayesian inference of species trees from multilocus data. Mol Biol Evol. 2010;27:570-80.

64. Bouckaert R, Vaughan TG, Barido-Sottani J, Duchene S, Fourment M, Gavryushkina A, et al. BEAST 2.5: an advanced software platform for Bayesian evolutionary analysis. PLoS Comput Biol. 2019;15:e1006650.

65. Rambaut A, Drummond AJ, Xie D, Baele G, Suchard MA. Posterior summarisation in Bayesian phylogenetics using Tracer 1.7. Syst Biol. 2018:67:901-4

66. Paradis E. pegas: an R package for population genetics with an integrated-modular approach. Bioinformatics. 2010;26:419-20.

67. Kass RE, Raftery AE. Bayes factors. J Am Stat Assoc. 1995;90:773-95.

68. Oaks JR, Cobb KA, Minin VN, Leache AD. Marginal likelihoods in phylogenetics: a review of methods and applications. Syst Biol. 2019;68:681-97.

69. Maturana Russel P, Brewer BJ, Klaere S, Bouckaert RR. Model selection and parameter inference in phylogenetics using nested sampling. Syst Biol. 2018;68:219-33.

70. Lartillot N, Philippe H. Computing Bayes factors using thermodynamic integration. Syst Biol. 2006:55:195-207.

71. Jeffreys H. Theory of probability. Oxford: Oxford University Press; 1961

72. Villacis AG, Bustillos JJ, Depickere S, Sanchez D, Yumiseva CA, TroyaZuleta A, et al. Would tropical climatic variations impact the genetic variability of triatomines: Rhodnius ecuadoriensis, principal vector of Chagas disease in Ecuador? Acta Trop. 2020;209:105530.
73. Lyman DF, Monteiro FA, Escalante AA, Cordon-Rosales C, Wesson DM, Dujardin J-P, et al. Mitochondrial DNA sequence variation among triatomine vectors of Chagas disease. Am J Trop Med Hyg 1999;60:377-86.

74. Diaz S, Panzera F, Jaramillo-O N, Perez R, Fernandez R, Vallejo G, et al. Genetic, cytogenetic and morphological trends in the evolution of the Rhodnius (Triatominae: Rhodniini) trans-Andean group. PLoS ONE. 2014;9:e87493.

75. Abad-Franch F, Monteiro FA. Biogeography and evolution of Amazonian triatomines (Heteroptera: Reduviidae): implications for Chagas disease surveillance in humid forest ecoregions. Mem Inst Oswaldo Cruz. 2007;102(Suppl. 1):57-70.

76. Abad-Franch F, Noireau F, Paucar CA, Aguilar VHM, Carpio CC, Racines VJ. The use of live-bait traps for the study of sylvatic Rhodnius populations (Hemiptera: Reduviidae) in palm trees. Trans R Soc Trop Med Hyg. 2000;94:629-30.

77. Moreno MJ, Galvão C, Jurberg J. Rhodnius colombiensis sp. n. da Colômbia, com quadros comparativos entre estruturas fálicas do gênero Rhodnius Stål, 1859 (Hemiptera, Reduviidae, Triatominae). Entomol Vectores. 1999;6:601-17.

78. Funk DJ, Omland KE. Species-level paraphyly and polyphyly: frequency, causes, and consequences, with insights from animal mitochondrial DNA. Annu Rev Ecol Evol Syst. 2003;34:397-423.

79. Hernandez-Castro LE, Paterno M, Villacis AG, Andersson B, Costales $J A$, De Noia M, et al. 2b-RAD genotyping for population genomic studies of Chagas disease vectors: Rhodnius ecuadoriensis in Ecuador PLoS Negl Trop Dis. 2017;11:e0005710.

80. Bargues MD, Klisiowicz DR, Gonzalez-Candelas F, Ramsey JM, Monroy C, Ponce C, et al. Phylogeography and genetic variation of Triatoma dimidiata, the main Chagas disease vector in Central America, and its position within the genus Triatoma. PLoS Negl Trop Dis. 2008;2:e233.

81. Monteiro FA, Peretolchina T, Lazoski C, Harris K, Dotson EM, AbadFranch F, et al. Phylogeographic pattern and extensive mitochondrial DNA divergence disclose a species complex within the Chagas disease vector Triatoma dimidiata. PLoS ONE. 2013;8:e70974.

82. Fitzpatrick S, Feliciangeli MD, Sánchez-Martín M, Monteiro FA, Miles MA. Molecular genetics reveal that silvatic Rhodnius prolixus do colonise rural houses. PLoS Negl Trop Dis. 2008;2:e210.

83. Pfeiler E, Bitler BG, Ramsey JM, Palacios-Cardiel C, Markow TA. Genetic variation, population structure, and phylogenetic relationships of Triatoma rubida and T. recurva (Hemiptera: Reduviidae: Triatominae) from the Sonoran desert, insect vectors of the Chagas' disease parasite Trypanosoma cruzi. Mol Phylogenet Evol. 2006;41:209-21.

84. Peretolchina T, Pavan MG, Correa-Antonio J, Gurgel-Gonçalves R, Lima MM, Monteiro FA. Phylogeography and demographic history of the Chagas disease vector Rhodnius nasutus (Hemiptera: Reduviidae) in the Brazilian Caatinga biome. PLoS Negl Trop Dis. 2018;12:e0006731.

85. Wiemers M, Fiedler K. Does the DNA barcoding gap exist?-A case study in blue butterflies (Lepidoptera: Lycaenidae). Front Zool. 2007:4:8.

86. Chavez T, Moreno J, Dujardin J-P. Isoenzyme electrophoresis of Rhodnius species: a phenetic approach to relationships within the genus. Ann Trop Med Parasitol. 1999;93:299-307.

87. Pita S, Panzera F, Ferrandis I, Galvão C, Gómez-Palacio A, Panzera Y. Chromosomal divergence and evolutionary inferences in Rhodniin based on the chromosomal location of ribosomal genes. Mem Inst Oswaldo Cruz. 2013;108:376-82.

88. Combes SA, Daniel TL. Shape, flapping and flexion: wing and fin design for forward flight. J Exp Biol. 2001;204:2073-85.

89. Patterson JS. Comparative morphometric and molecular genetic analyses of Triatominae (Hemiptera: Reduviidae). PhD thesis, London School of Hygiene Tropical Medicine, University of London, UK; 2007. doi: https://doi.org/10.17037/PUBS.00682370.

90. Miles MA, de Souza AA, Povoa MM. Chagas disease in the Amazon basin III. Ecotopes of ten triatomine bug species (Hemiptera: Reduviidae) from the vicinity of Belém, Pará State, Brazil. J Med Entomol. 1981;18:266-78

91. Merrick MJ, Koprowski JL, Gwinn RN. Sciurus stramineus (Rodentia: Sciuridae). Mamm Species. 2012;44:44-50. 
92. Araujo AN, Gontijo NF, Guarneri AA, Gontijo AF, Soares AC, Pereira $\mathrm{MH}$. Electromyogram of the cibarial pump and the feeding process in hematophagous Hemiptera. In: Mizrahi J, editor. Advances in applied electromyography. Rijeka: InTech; 2011. p. 137-58.

93. Grijalva MJ, Teran D, Dangles O. Dynamics of sylvatic Chagas disease vectors in coastal Ecuador is driven by changes in land cover. PLoS Negl Trop Dis. 2014;8:e2960.

94. Gaunt MW, Miles MA. The ecotopes and evolution of triatomine bugs (Triatominae) and their associated trypanosomes. Mem Inst Oswaldo Cruz. 2000;95:557-65.

95. Dias FBS, Bezerra CM, Machado EMM, Casanova C, Diotaiuti L. Ecological aspects of Rhodnius nasutus Stål, 1859 (Hemiptera: Reduviidae: Triatominae) in palms of the Chapada do Araripe in Ceará, Brazil. Mem Inst Oswaldo Cruz. 2008;103:824-30.

96. Stevens M, Merilaita S. Animal camouflage: current issues and new perspectives. Phil Trans R Soc B. 2009;364:423-7.

97. Renjifo-Correa L, Abad-Franch F, Martinez-Hernandez F, SalazarSchettino PM, Tellez-Rendon JL, Villalobos G, et al. A biogeographicecological approach to disentangle reticulate evolution in the Triatoma phyllosoma species group (Heteroptera: Triatominae), vectors of Chagas disease. J Zool Syst Evol Res. 2021;59:94-110.

98. Karpestam E, Merilaita S, Forsman A. Colour polymorphism protects prey individuals and populations against predation. Sci Rep. 2016;6:22122
99. Breniere SF, Salas R, Buitrago R, Bremond P, Sosa V, Bosseno M-F, et al. Wild populations of Triatoma infestans are highly connected to intraperidomestic conspecific populations in the Bolivian Andes. PLoS ONE. 2013;8:e80786.

100. Almeida CE, Faucher L, Lavina M, Costa J, Harry M. Molecular individualbased approach on Triatoma brasiliensis: inferences on triatomine foci, Trypanosoma cruzi natural infection prevalence, parasite diversity and feeding sources. PLoS Negl Trop Dis. 2016;10:e0004447.

101. Kamimura EH, Viana MC, Lilioso M, Fontes FHM, Pires-Silva D, ValençaBarbosa C, et al. Drivers of molecular and morphometric variation in Triatoma brasiliensis (Hemiptera: Triatominae): the resolution of geometric morphometrics for populational structuring on a microgeographical scale. Parasit Vectors. 2020;13:455.

102. Dumonteil E, Tripet F, Ramirez-Sierra MJ, Payet V, Lanzaro G, Menu F. Assessment of Triatoma dimidiata dispersal in the Yucatan Peninsula of Mexico by morphometry and microsatellite markers. Am J Trop Med Hyg. 2007;76:930-7.

\section{Publisher's Note}

Springer Nature remains neutral with regard to jurisdictional claims in published maps and institutional affiliations.
Ready to submit your research? Choose BMC and benefit from:

- fast, convenient online submission

- thorough peer review by experienced researchers in your field

- rapid publication on acceptance

- support for research data, including large and complex data types

- gold Open Access which fosters wider collaboration and increased citations

- maximum visibility for your research: over $100 \mathrm{M}$ website views per year

At BMC, research is always in progress.

Learn more biomedcentral.com/submissions 